\title{
System Dynamics Model for VMI\&TPL Integrated Supply Chains
}

\author{
Guo Li, ${ }^{1}$ Xiaojing Wang, ${ }^{2}$ and Zhaohua Wang ${ }^{1}$ \\ ${ }^{1}$ School of Management and Economics, Beijing Institute of Technology, Beijing 100081, China \\ ${ }^{2}$ Ningbo Modern Logistics Planning Institute, Ningbo, Zhejiang 315042, China \\ Correspondence should be addressed to Guo Li; lg4229682@163.com
}

Received 29 July 2013; Accepted 28 September 2013

Academic Editor: Tinggui Chen

Copyright (C) 2013 Guo Li et al. This is an open access article distributed under the Creative Commons Attribution License, which permits unrestricted use, distribution, and reproduction in any medium, provided the original work is properly cited.

\begin{abstract}
This paper establishes VMI-APIOBPCS II model by extending VMI-APIOBPCS model from serial supply chain to distribution supply chain. Then TPL is introduced to this VMI distribution supply chain, and operational framework and process of VMI\&TPL integrated supply chain are analyzed deeply. On this basis VMI-APIOBPCS II model is then changed to VMI\&TPL-APIOBPCS model and VMI\&TPL integrated operation mode is simulated. Finally, compared with VMI-APIOBPCS model, the TPL's important role of goods consolidation and risk sharing in VMI\&TPL integrated supply chain is analyzed in detail from the aspects of bullwhip effect, inventory level, service level, and so on.
\end{abstract}

\section{Introduction}

Under vendor-managed inventory (VMI) operation mode, many suppliers outsource their logistics to third-party logistics (TPL) due to their poor logistics capabilities. So far, that TPL participates in VMI has been widely used in many industries. For example, Dell and Lenovo both chose Burlington Company to help them operate VMI service, and Wuhan Shenlong Automobile Company in China allows GEFCO to provide VMI service with components supply. On the one hand, this integrated operational model combining VMI with TPL ensures that the supply chain information is shared fully on one central platform. On the other hand, it can take full advantage of TPL and reduce the total operational cost of the supply chain.

As to the research of VMI\&TPL integrated replenishment and delivery, Çetinkaya et al. [1] take Dell as an example, which outsources VMI business to Burlington Logistics, and analyze TPL replenishment and delivery strategies. They do not only consider the optimal delivery strategies about logistics outsourcing but also find out differences of the optimal delivery strategies before and after outsourcing. Based on the above study, Çetinkaya and Lee [2] consider the time-based delivery policy and obtain the optimal delivery time structure with transportation lot constraints and capability limitations while the demand of retailers obeys the Poisson distribution. Lee et al. [3] assume that the replenishment and delivery can be started at the beginning of each period with determined demand and finite horizon and that the lead time for delivery of the replenishment is zero. They consider the problem of inventory and transportation integration, which is similar to Çetinkaya and Lee [2]. In order to achieve economies of transport scale, TPL implements goods consolidation strategy. As a result, products may be delivered to retailers in an earlier or later time, which would lead to the inventory cost or shortage cost. Their research shows that the problem is NP hard and that the demand in each period must be satisfied in just one delivery, with transportation constraints. Furthermore, they point out that if each delivery can meet demands in several consecutive cycles and the demand in the first and last periods may be met by two deliveries then the optimal replenishment and delivery policy exists. They even propose a polynomial algorithm to solve the above problem of optimal replenishment and delivery. Çetinkaya et al. [4] provide a foundation for a comparison of the impact of timebased versus quantity-based consolidation in the context of integrated inventory and transportation decisions. Numerical and analytical results verify that quantity-based consolidation is superior to the time-based version in terms of the resulting cost. Furthermore, several easily implementable TQ-based policies are proposed and their impacts on cost and service 
are compared to those of time-based and quantity-based versions via simulation. Mutlu et al. [5] extend the results in Çetinkaya et al. [4] and develop an analytical model for computing the expected long-run average cost of a consolidation system implementing a TQ-based policy. The presented analytical results prove that (i) the optimal TQbased policy outperforms the optimal time-based policy and (ii) the optimal quantity-based policy is superior to the other two (i.e., optimal time-based and TQ-based) policies in terms of cost. Considering the expected maximum waiting time as a measure of timely delivery performance, however, they numerically demonstrate that the TQ-based policies improve on the quantity-based policies significantly with only a slight increase in the cost.

Besides, some scholars consider replenishment strategies of TPL in VMI mode under different conditions, such as Çetinkaya et al. [6], Dejonckheere et al. [7], Wikrom et al. [8-11], Lee [12], Hwang [13], and Howard and Marklund [14]. Çetinkaya et al. [6] consider different delivery and replenishment strategies under two kinds of transportation modes. One is self-transportation which is the same as in the above literature. The other one is outsourcing transportation. As transportation providers will take the discount policy to encourage suppliers to transport more, transportation cost may be a piecewise function in this situation. They propose two kinds of delivery and replenishment strategies based on time and quantity under different transportation modes. Dejonckheere et al. [7] investigate the utilization of a linear (Type II) or quadratic (Type III) instead of a constant (Type I) exponential smoothing forecasting mechanism in the continuous-time APIOBPCS model. Mustafa et al. [15] consider the impact of coordinated replenishment and shipment in inventory/distribution systems and analyze a system with multiple retailers and one outside supplier. They present a centralized ordering policy that orders for all retailers and some other well-known policies like (a) canorder policy, (b) echelon inventory policy, and (c) fixedreplenishment interval policy. Leopoldo et al. [16] present an alternative heuristic algorithm to solve the vendor-managed inventory system with multiproduct and multiconstraint based on EOQ with backorders considering two classical backorders costs: linear and fixed. Sadeghia et al. [17] develop a constrained multivendor multiretailer single-warehouse (MV-MR-SW) supply chain, in which both the space and the annual number of orders of the central warehouse are limited. Since the problem is formulated into an integer nonlinear programming model, the metaheuristic algorithm of particle swarm optimization (PSO) is presented to find an approximate optimum solution of the problem. In the proposed PSO algorithm, a genetic algorithm (GA) with an improved operator, namely, the boundary operator, is employed as a local searcher to turn it to a hybrid PSO. Moreover, Harigaa et al. [18] consider a supply chain composed of a single vendor and multiple retailers operating under a VMI contract that specifies limits on retailers' stock levels. They address the problem of synchronizing the vendor's cycle time with the buyers' unequal ordering cycles by developing a mixed integer nonlinear program that minimizes the joint relevant inventory costs under storage restrictions.
As to logistics optimization based on system dynamics, Towill [19] establishes a new inventory-and-order-based production and control system (IOBPCS) by extending production inventory control (PIC) [20] and then optimizes the system by using the coefficient plane model. Sterman [21] constructs a general inventory management model, making use of the system dynamics, and points out that different complexity of feedback in supply chain inventory management system and the pressure of time usually lead decision makers to misunderstand the feedback information and thus make irrational decisions. John et al. [22] introduce WIP feedback control mechanism into IOBPCS model and expand the IOBPCS model into APIOBPCS. Later, MasonJones et al. [23] analyze the function of WIP feedback control mechanism in the models by comparing IOBPCS and APIOBPCS. Disney and Towill $[24,25]$ construct VMIAPIOBPCS model and analyze VMI strategy's effects on the supply chain bullwhip effect, customer service level and inventory costs with the assumption that the enterprises face the obvious fluctuations of demand. Besides, they optimize the VMI-APIOBPCS model and obtain the optimal parameters after considering different weights of production adjustment costs, different proportions of inventory costs, and different coefficients of safety stock. Disney and Towill $[24,25]$ study a simple vendor-managed inventory (VMI) supply chain consisting of one production unit and one distributor. In VMI systems all supply points in the chain have access to stock positions for setting production and distribution targets. The discrete-time APIOBPCS model is used to describe the dynamics of the manufacturing unit. Pure delay is initially utilized to model the production delay. The only difference to the APIOBPCS structure presented previously is that instead of the demand signal CONS the manufacturing facility receives a "virtual" consumption signal. This is caused by adding in each time period the demand signal received by the distributor to the difference between the current time period and the previous period reorder-point. The system is checked for stability. The stability criteria that are produced are also valid for the standard APIOBPCS model, since the distributor's policy described previously is a stable feedforward element. One year later, Disney and Towill [26-28] analyze deeply how VMI affects the bullwhip effect in the supply chain and compare the VMI supply chain's expected performance with that of a traditional supply chain. VMI strategy shows that it has better reactions when demand is not steady, and this kind of instability may be caused by discounts available for orders or price's changes. Besides, the restoration of inventory level will be improved dramatically by VMI strategy. Moreover, Disney and Towill [26-28] concentrate on VMI strategy's effects on transport operations in supply chain, especially the batch problem in transportation strategy. By using system dynamics, they establish three different kinds of models-the traditional one, the internal integrated one, and the VMI one. The simulation case shows that VMI model can reduce transportation frequency by adopting a larger batch without influencing the dynamic performance of the entire supply chain. Wikner [29] presents a methodology that introduces structure dependencies of MLMS systems in the IOBPCS production control framework. The methodology 
uses matrix representation to account for multiple informational channels. It is shown that for a single-level singlestage system the model is reduced to the standard IOBPCS format. The extended model has the capability to describe the dynamics of both pull-driven (base stock, kanban) and pushdriven (MRP) policies.

In the other field, through STELLA/iThink software platform, Chen et al. [30] construct a system dynamics model of inventory management, analyze system structures and operational mechanisms of VMI inventory management and traditional inventory management, and finally compare their operational performance. Yang and Liu [31] extend VMIAPIOBPCS model from one supplier-one retailer supply chain to one supplier-two retailers supply chain and then construct VMI-APIOBPCS II. With the integration of TPL, they establish VMI\&TPL-APIOBPCS model and the simulation shows that TPL can help reduce bullwhip effect in the supply chain availably. Cho and Lazaro [32] extend PID controller for just-in-time production scheduling. Lin et al. [33] develop a fuzzy system dynamic to simulate vendormanaged inventory, automatic pipeline, and inventory-andorder-based production control system (VMI-APIOBPCS) model based on fuzzy difference equations, and these operators of difference equations adopt the weakest $t$-norm (TW) operators. The results of fuzzy VMI-APIOBPCS model can provide the whole extended information regarding the system behavior uncertainties for the decision makers with fuzzy interval.

After that Darya and Martin [34] address the steadystate optimization of a supply chain model that belonged to the class of vendor-managed inventory, automatic pipeline, and inventory-and-order based production control systems (VMI-APIOBPCS). They optimize the supply chain with the so-called normal vector method, which has specifically been developed for the economic optimization of uncertain dynamical systems with constraints on dynamics. Kristianto et al. [35] propose an adaptive fuzzy control application to support a vendor-managed inventory (VMI). The methodology applies fuzzy control to generate an adaptive smoothing constant in the forecast method, production, and delivery plan to eliminate, for example, the rationing and gaming or the Houlihan effect and the order batching effect or the Burbidge effects and finally the bullwhip effect. In order to improve the level of integration in all aspects of supply chain reconfiguration, Kristianto et al. [36] construct an optimum supply chain network by combining optimization at the strategic and tactical level. A system dynamic based computer simulation model is used to validate the operations of the supply chain. The performance of the system is measured in terms of backorders and inventory level. The results and analysis indicate that fewer stockholding points and a shorter review period of demand can improve performance in this respect.

Our work differs from these studies in important aspects. First of all, these models are mainly constructed based on two echelon supply chains, that is, Disney and Towill [2428], Lin et al. [33], Darya and Martin [34], and Kristianto et al. $[35,36]$. In our model, however, VMI\&TPL integrated operational model is a relatively complex three-echelon
TABLE 1: Definitions of parameters and variables.

\begin{tabular}{|c|c|}
\hline \multicolumn{2}{|c|}{$T_{i}$ : inventory adjustment time $T_{a}$ : demand smooth time } \\
\hline$T_{p}:$ production delay time & $\begin{array}{l}T_{\widehat{p}}: \text { estimated value of production } \\
\text { delay time }\end{array}$ \\
\hline CON: demand rate & ACON: demand rate after forecast \\
\hline ORT: production rate & CRT: production fulfillment rate \\
\hline TINV: target inventory level & INV: actual inventory level \\
\hline EINV: inventory deviation & WIP: work-in-process \\
\hline $\begin{array}{l}\text { TWIP: target work-in- } \\
\text { process }\end{array}$ & EWIP: work-in-process deviation \\
\hline
\end{tabular}

supply chain system. The TPL role integrated with VMI should be explored. Furthermore, we also model VMI\&TPL integrated supply chain from aspects of bullwhip effect, inventory levels, service level with stochastic demand, and other uncertainties, compared with VMI-APIOBPCS model. Since system dynamics suit researches of complex systems very well, VMI\&TPL-APIOBPCS model is constructed based on system dynamics to simulate and analyze the performance of VMI\&TPL integrated operational model.

\section{IOBPCS Model Family}

2.1. Definitions of Parameters and Variables. Table 1 is the definitions of parameters and variables used in this paper.

2.2. IOBPCS Model. As shown in Figure 1, inventory levels of work-in-process and finished products can be controlled by production order rate in IOBPCS system, and customers' demand is met by inventory.

Figure 2 is the causal relationship in IOBPCS model, including 4 main parts, which are demand forecast feedforward loop, production delays, inventory feedback loop, and target inventory. Production delays refer to the time from production orders to production fulfillment rate. In series IOBPCS models, it is assumed that production process in production lead time meets a certain order, and orders keep a sequence of events. Demand forecast feed-forward loop refers to the demand forecasting mechanism which is used to predict the demand in and after production lead time. Inventory feedback loop actually is a kind of inventorydeviation adjustment mechanism. It is necessary to produce more goods to adjust inventory deviation when the actual inventory level and target inventory level differ greatly.

The productivity in IOBPCS model is decided by the demand forecasting mechanism and the inventory deviation adjustment mechanism, while the inventory deviation adjustment mechanism is decided by the inventory adjustment time and the target inventory level, and the demand forecasting mechanism is decided by the demand smooth time. Therefore, IOBPCS system optimization includes the definition of two basal parameters, such as demand smooth time and inventory deviation adjustment time. When designing the best production control strategy, cost from two sides should be balanced, including production cost due to production 


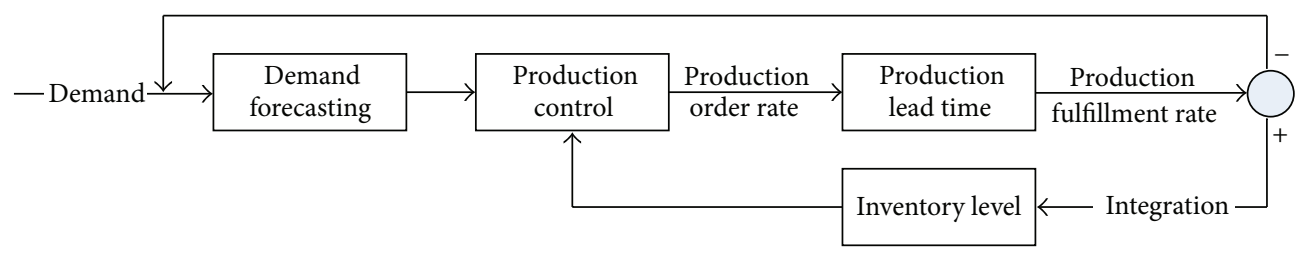

FIGURE 1: IOBPCS model of production and inventory system.

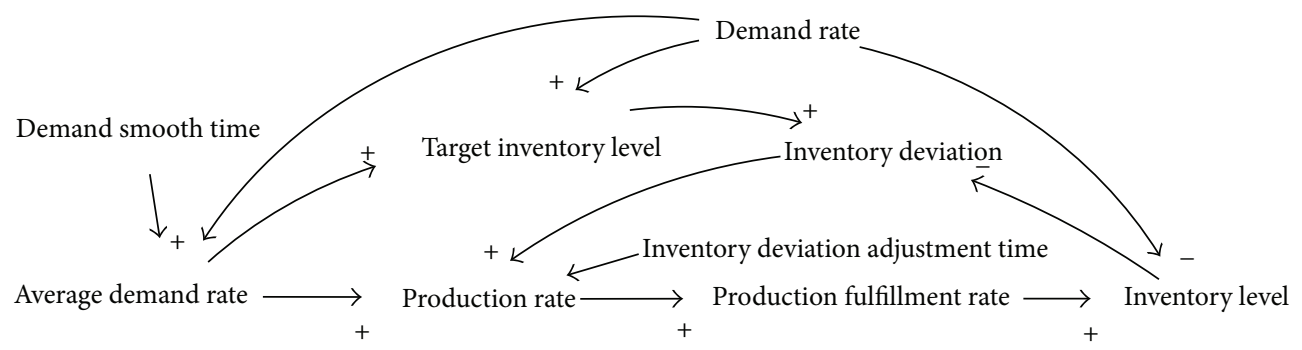

FIgURE 2: IOBPCS model causal relationship.

fluctuation and the inventory cost (or shortage cost) as the inventory level changes.

2.3. IOBPCS Expansion Model. After many scholars amending and improving the model based on IOBPCS model, now it has been turned into an IOBPCS model family consisting of five parts as Figure 3 shows.

2.3.1. Production Delay. The lead time of production delays can be regarded as production rhythm smooth time, which describes the speed of adjusting production rhythm to production order changes (ORATE). The production delay is one of the system characteristics, which cannot be controlled at random by the system's designers, but designing different delay models will have an important effect on the entire system's performance. Formula (1) is the dynamic behavior of the three delay models:

$$
G_{p}(s)=\frac{1}{\left(\left(T_{p} / n\right) s+1\right)^{n}},
$$

where $n=1$, first-order delay; $n=3$, third-order delay; $n=8$, pure delay; $T_{p}$ is production delay time.

2.3.2. Target Inventory Level (DINV). In IOBPCS model, target inventory level is a fixed value or the integer multiple of the demand forecasting number (ACON) after smoothing. Target inventory level is variable in VIOBPCS. Compared with IOPBPCS, the width of ORATE is larger, but the inventory adjustment response time is shorter. The only difference between APIOBPCS model and APVIOBPCS model lies in the setting of target inventory. In APIOBPCS model, target inventory level DINV $=k * \mathrm{ACON}$, where $k$ is a positive integer.

2.3.3. Demand Forecasting Mechanism. Demand forecasting mechanism is an important part of the feed-forward loop.
Demand forecasting mechanism is measured by exponential smoothing method in most literatures, because exponential smoothing method comprehensively includes all the historical information and is easy to use and to formulate a model. Exponential forecasting method (e.g., single exponential smoothing method, double exponential smoothing method, and triple exponential smoothing method) makes the steadystate error of system inventory in phase step and slope demand zero, but the steady-state error of system inventory becomes larger and larger when the demand function is a parabola.

Single exponential smoothing transfer function in $s$ region is

$$
G_{a}(s)=\frac{1}{T_{a} s+1} .
$$

Double exponential smoothing transfer function in $s$ region is

$$
G_{a}(s)=\frac{2 T_{a} s+1}{T_{a}^{2} s^{2}+2 T_{a} s+1}
$$

Triple times exponential smoothing transfer function in $s$ region is

$$
G_{a}(s)=\frac{3 T_{a}{ }^{2} s^{2}+3 T_{a} s+1}{T_{a}^{3} s^{3}+3 T_{a}^{2} s^{2}+3 T_{a} s+1} .
$$

2.3.4. Inventory Deviation Adjustment Mechanism. Inventory deviation adjustment mechanism is an inventory feedback loop which controls inventory deviation by controlling productivity. Inventory adjustment mechanism needs to consider production delay effect which means that only after a regular period of time can the controlling decision about productivity adjust the inventory level. The purpose of inventory adjustment is to reach target inventory level in a period of time $\left(T_{i}\right)$. When the adjustment time is shorter, 


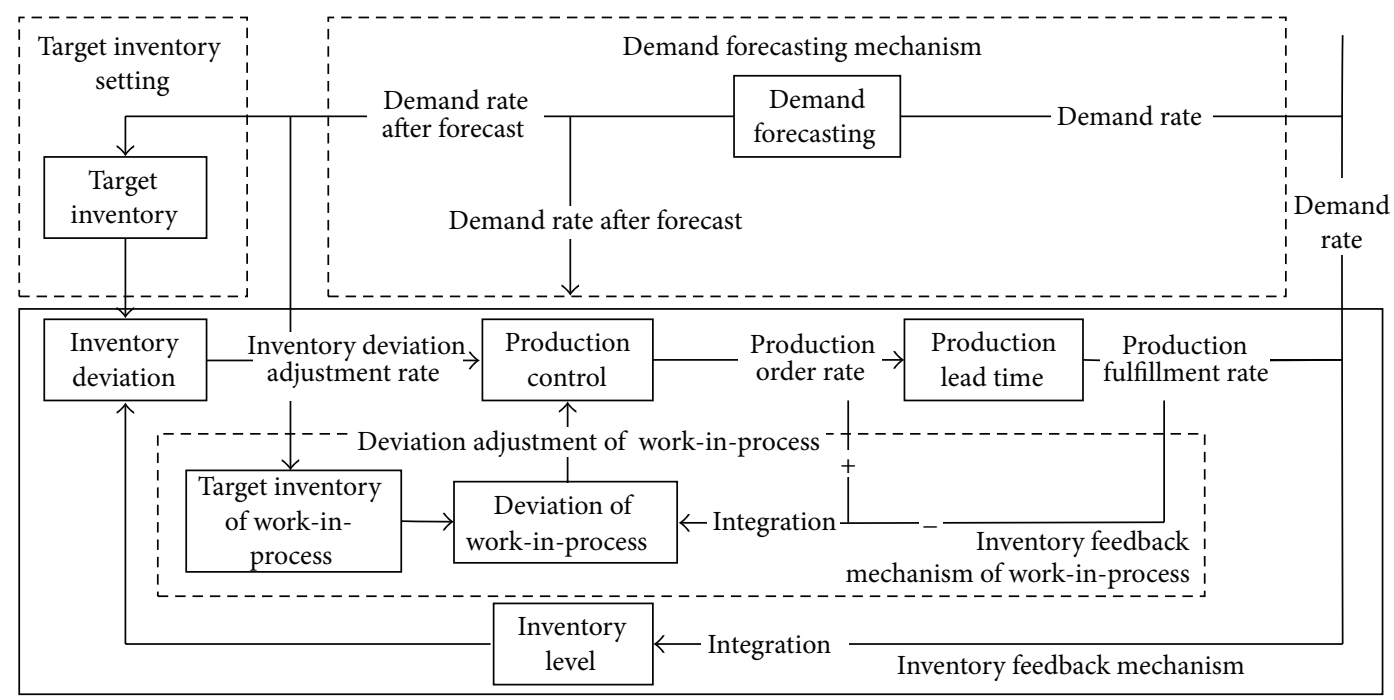

FIgURE 3: The main parts of expanded IOBPCS model.

the inventory can adjust faster. As a result, shortage cost and risks become smaller. However, it requires manufacturers for a higher production capacity, because the system needs to correct the early inventory deviation in a short time by adjusting productivity, and this can lead to higher cost of production and work-in-process inventory.

\subsubsection{WIP Inventory Deviation Adjustment Mechanism. WIP} inventory deviation is caused by actual work-in-process inventory in contradiction with target work-in-process inventory when demand changes. WIP adjustment mechanism adjusts inventory deviation by controlling productivity so that it can reach the target value in a period of time $\left(T_{w}\right)$. Therefore, WIP inventory deviation adjustment rate is one of the three parts of the productivity control mechanisms. It is necessary to study and analyze the production process and get a relatively exact estimate value by making statistical analysis of production delay time before designing the productivity control mechanism. If the observed production delay time is different from actual time, inventory level in steady-state will not be in accord with target inventory level, which will cause more risk of inventory or shortage.

2.4. APIOBPCS Model. Figure 4 is a block diagram of APIOBPCS model lying in $s$ region. The purpose of system designing is to find a proper target inventory level and design three optimal control mechanisms (demand forecasting mechanism, inventory deviation adjustment, and WIP inventory deviation adjustment mechanism), in order to minimize system cost, including production cost and inventory cost.

In general, inventory dynamic fluctuation is measured by inventory rising time and adjustment time and overshoot, and productivity dynamic change is analyzed by frequency response method.

Here is the main control mechanism of APIOBPCS model in phase-step demand.
(1) Forecasting mechanism. Formula (5) is the transfer function in $s$ region with single exponential smoothing:

$$
G_{a}(s)=\frac{1}{T_{a} s+1}
$$

(2) Target inventory setting. TINV $=0$.

(3) Production process. Formula (6) is the transfer function in $s$ region with first-order delay:

$$
G_{p}(s)=\frac{1}{T_{p} s+1} .
$$

As a result, two important transfer functions about productivity and changes in inventory level can be obtained as follows:

$$
\begin{aligned}
F_{1}(s)= & \frac{\operatorname{ORT}(s)}{\operatorname{CON}(s)} \\
& =\frac{T_{p} T_{i} s+T_{w}+\left(T_{a}+T_{i}\right) T_{w} s}{\left(1+T_{a} s\right)\left[T_{i} T_{w} T_{p} s^{2}+T_{i} s\left(T_{p}+T_{w}\right)+T_{w}\right]},
\end{aligned}
$$

$F_{2}(s)$

$$
\begin{aligned}
& =\frac{\operatorname{INV}(s)}{\operatorname{CON}(s)} \\
& =\frac{T_{i}\left(T_{\hat{p}}-T_{p}\right)-T_{i} T_{p} T_{w} s-T_{i} T_{p} T_{a} s-T_{i} T_{w} T_{a} s-T_{a} T_{i} T_{w} T_{p} s^{2}}{\left(1+T_{a} s\right)\left[T_{i} T_{w} T_{p} s^{2}+T_{2}\left(T_{p}+T_{w}\right) s+T_{w}\right]} .
\end{aligned}
$$

\section{VMI-APIOBPCS Model}

3.1. Definitions of Parameters and Variables. Table 2 is the definitions of parameters and variables used in this paper. 


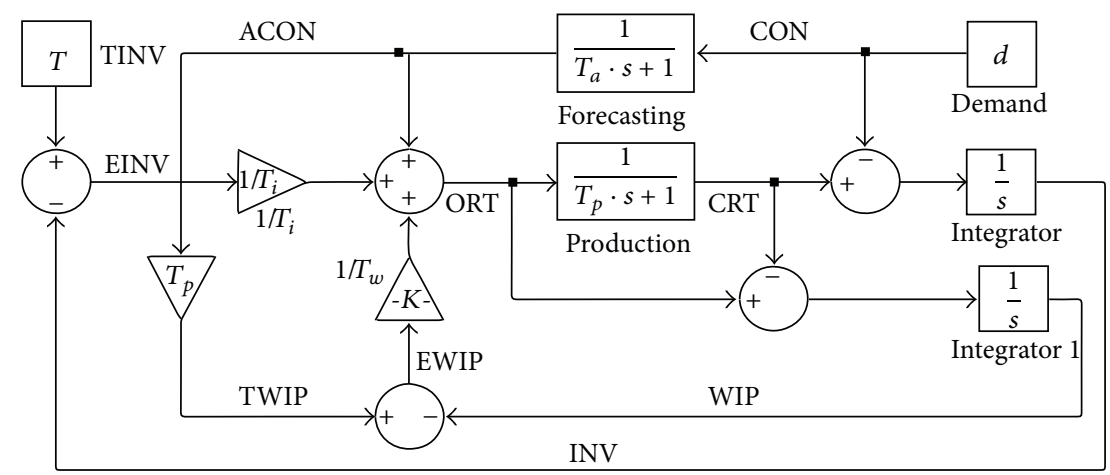

FIGURE 4: Block diagram of APIOBPCS model.

TABLE 2: Definitions of parameters and variables.

Parameters and variables of suppliers

VCON: demand rate of suppliers

VINV: inventory level of suppliers

WIP: work-in-process inventory level

EINV: inventory deviation

ORT: productivity of suppliers

$T_{i}$ : adjustment time of system inventory deviation

$T_{w}$ : work-in-process inventory deviation adjustment time

AEWIP: work-in-process inventory deviation regulation factor

AEINV: deviation adjustment rate of system inventory
$\mathrm{CON}$ : demand rate of retailers

RINP: inventory level of retailers (including inventory on the

way)

G: safety inventory factor of retailers

SRT: delivering rate to retailers

DSS: reorder-point of retailers variation

GIT: inventory of distributors on the way

RINV: actual inventory level of retailers

L: transportation time from suppliers to retailers

ETQ: economic order quantity
AVCON: demand factor of suppliers after smoothing

TINV: system target inventory level

TWIP: target work-in-process inventory level

EWIP: deviation of work-in-process inventory

CRT: production fulfillment rate of suppliers

$T_{a}$ : demand rate of suppliers smooth time

$T_{p}$ : production delay time of suppliers

Parameters and variables of retailers

ACON: demand rate of retailers after forecasting

SS: safety inventory level

ROP: reorder-point of distributors

In VMI operation mode, retailers share inventory information and sales information with suppliers dynamically and determine the customer service level together with suppliers. According to the fixed customer service level, suppliers choose quantity-based delivering model, which means that vehicle shipped way is chosen in order to guarantee economical efficiency of transportation when the total inventory level is lower than the reorder-point. Figure 5 is VMI-APIOBPCS system dynamics model.

Here are the relational formulas in VMI-APIOBPCS model. They are as follows.

\subsubsection{Suppliers Production or Replenishment Mechanism}

(1) Demand forecasting mechanism:

$$
\operatorname{AVCON}_{t}=\operatorname{AVCON}_{t-1}+\frac{\operatorname{VCON}_{t}-\mathrm{AVCON}_{t-1}}{1+T_{a}} .
$$

(2) Target work-in-process inventory level:

$$
\mathrm{TWIP}_{t}=\mathrm{AVCON}_{t} \times T_{P}
$$




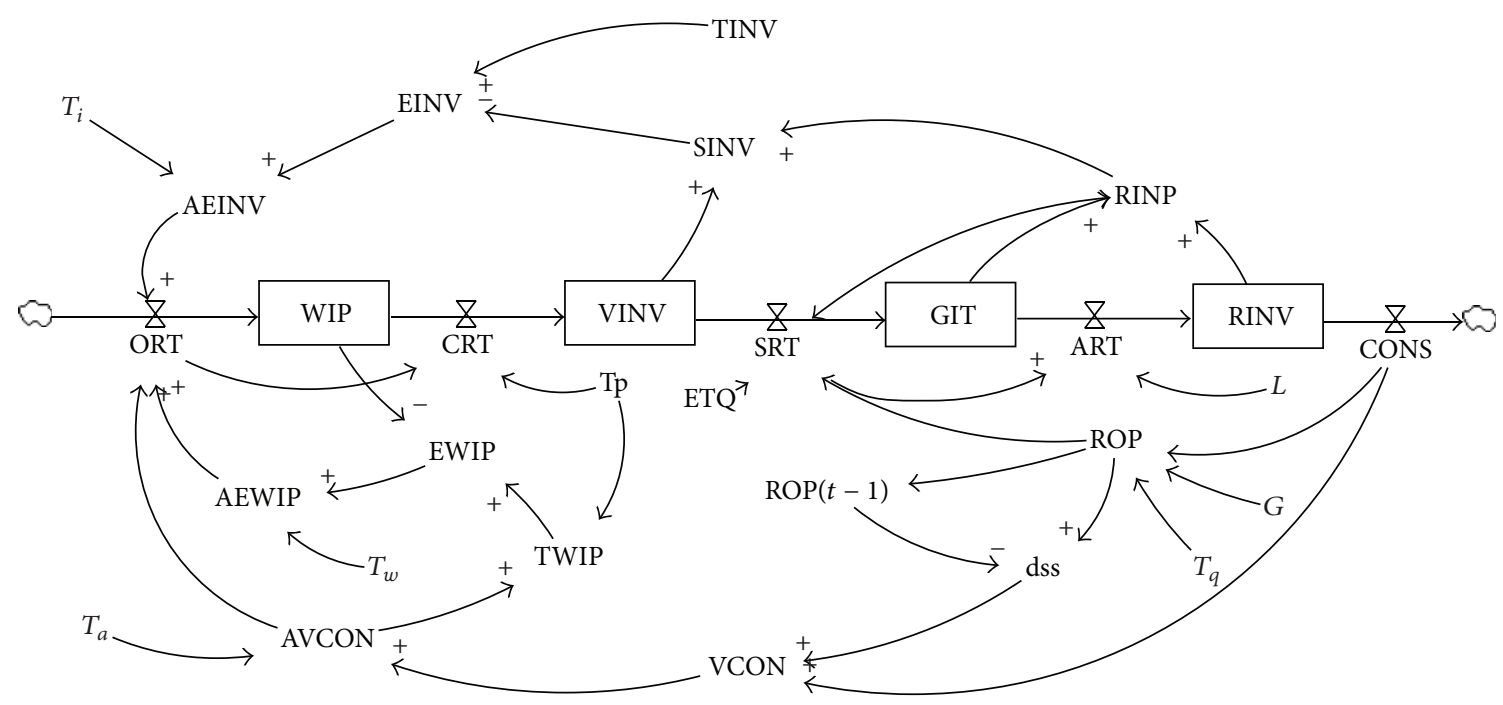

FIGURE 5: VMI-APIOBPCS system dynamics model.

(3) Work-in-process inventory level:

$$
\mathrm{WIP}_{t}=\mathrm{WIP}_{t-1}+\mathrm{ORT}_{t}-\mathrm{CRT}_{t} .
$$

(4) Finished goods inventory level:

$$
\mathrm{VINV}_{t}=\mathrm{VINV}_{t-1}+\mathrm{CRT}_{t}-\mathrm{SRT}_{t} .
$$

(5) Target inventory level:

$$
\mathrm{TINV}_{t}=\mathrm{AVCON}_{t} \times T_{s}
$$

(6) System inventory level:

$$
\operatorname{SINV}_{t}=\operatorname{VINV}_{t}+\mathrm{RINV}_{t}
$$

(7) Finished goods fulfillment rate:

$$
\mathrm{CRT}_{t}=\operatorname{delay}\left\{\mathrm{ORT}_{t}, T_{p}\right\}
$$

(8) Productivity:

$$
\mathrm{ORT}_{t}=\mathrm{AVCON}_{t}+\mathrm{AEINV}_{t}+\mathrm{AEWIP}_{t}
$$

(9) Inventory deviation adjustment rate:

$$
\mathrm{AEINV}_{t}=\frac{\operatorname{TINV}_{t}-\mathrm{SINV}_{t}}{T_{i}} .
$$

(10) Work-in-process inventory deviation adjustment rate:

$$
\mathrm{AEWIP}_{t}=\frac{\mathrm{TWIP}_{t}-\mathrm{WIP}_{t}}{T_{w}} .
$$

\subsubsection{Suppliers Delivering Mechanism}

(1) Reorder-point of retailers:

$$
\mathrm{ROP}_{t}=\mathrm{ROP}_{t-1}+\frac{\mathrm{SS}_{t}-\mathrm{ROP}_{t-1}}{1+T_{q}} .
$$

(2) Inventory levels of retailers:

$$
\mathrm{RINP}_{t}=\mathrm{RINV}_{t}+\mathrm{GIT}_{t}
$$

(3) Order arrival rate:

$$
\mathrm{ART}_{t}=\operatorname{delay}\left\{\mathrm{SRT}_{t}, L\right\}
$$

(4) Safety inventory setting of retailers:

$$
\mathrm{SS}_{t}=\mathrm{CON}_{t} \times G \text {. }
$$

\subsubsection{Information Sharing Mechanism in VMI Supply Chain}

(1) Suppliers can get customers' demand in time and obtain the actual total customer demand downstream through terminal customer information, including the terminal customer demand and changes of reorder-points of downstream retailers:

$$
\mathrm{VCON}_{t}=\mathrm{CON}_{t}+\mathrm{dSS}_{t}=\mathrm{CON}_{t}+\mathrm{ROT}_{t}-\mathrm{ROT}_{t-1} .
$$

(2) Suppliers can check the inventory level of downstream retailers so that they can get the total supply chain inventory level which can optimize the total supply chain inventory decision:

$$
\mathrm{SINV}_{t}=\mathrm{RINP}_{t}+\mathrm{VINV}_{t}
$$




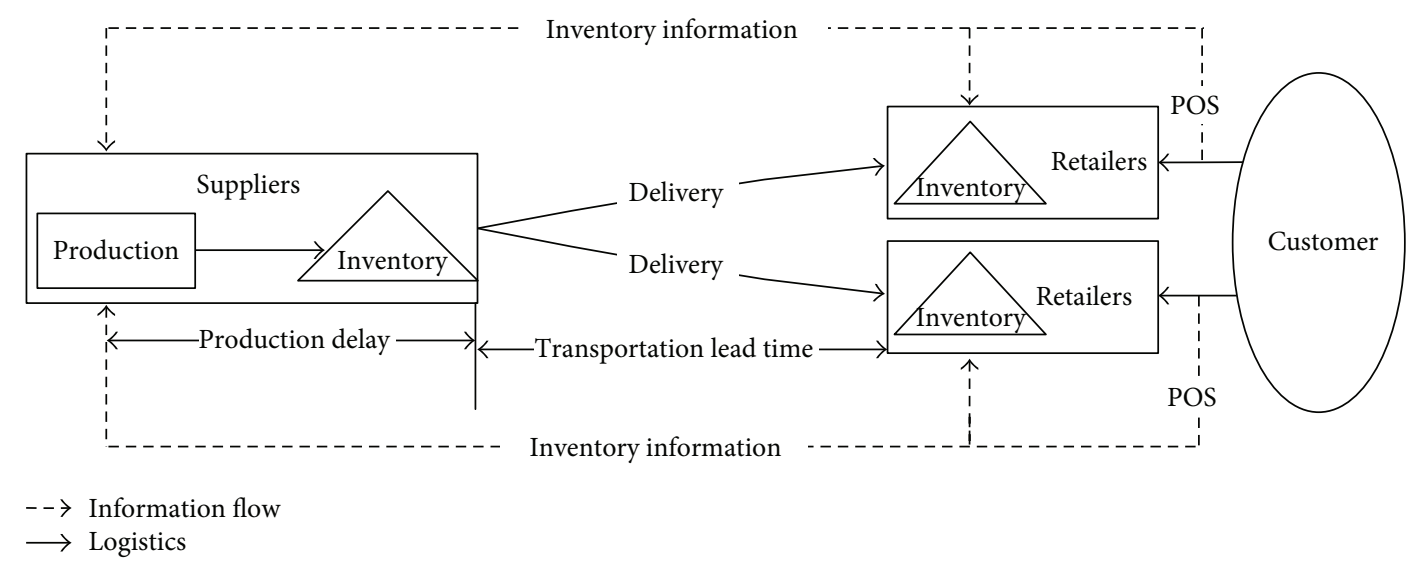

FIGURE 6: Operation mode of VMI distribution supply chain.

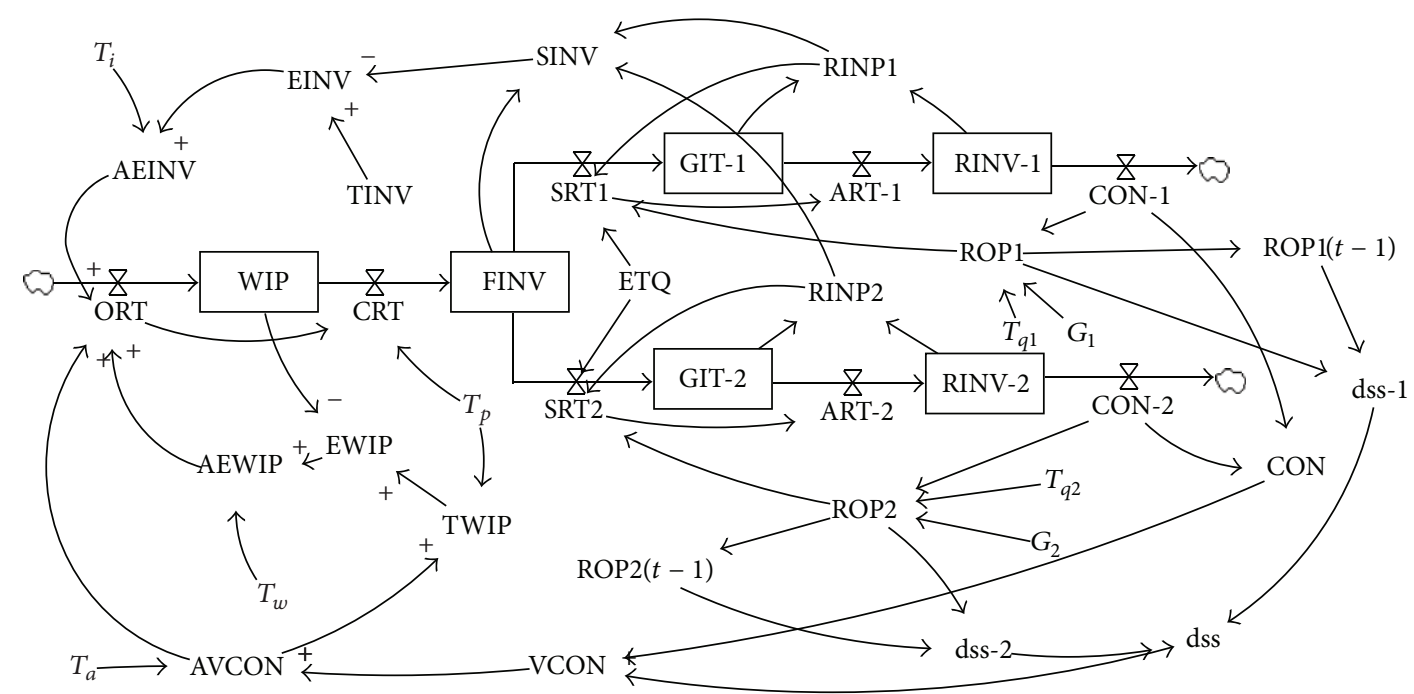

FIGURE 7: VMI-APIOBPCS II system dynamics model.

3.2. VMI Distribution Supply Chain. In the actual operational process, suppliers can adopt VMI model on multiple downstream retailers. According to the aforementioned VMI serial supply chain when suppliers provide multiple retailers downstream with VMI service, they can get VMI distribution supply chain, as Figure 6 shows, including one supplier and two retailers.

VMI-APIOBPCS II model as shown in Figure 7 is constructed based on the operation mode in Figure 6.

\section{VMI\&TPL-APIOBPCS Model}

\subsection{VMI Operational Process Based on TPL}

4.1.1. VMIßTPL Integrated Operation Mode. To decrease the logistics cost and avoid the delivery risks in VMI system, in practice an upstream enterprise normally prefers to outsource its purchasing business to the third-party logistics (TPL) and requires his supplier to keep the inventory in the warehouse operated by TPL. For example, BAX Global is responsible for Apple, Dell, IBM, and other IT companies with their supplies in Southeast Asia, and United Parcel Service manages goods and materials procurement for Fender overseas and achieves its integration of process in distribution. Besides, Shanghai Volkswagen and Wuhan Shenlong Automobile adopt VMI\&TPL integrated operation mode to effectively support the mixed flow job shop manufacturing with JIT delivering components to the work station directly.

After TPL is introduced into VMI, we consider the supply chain including one supplier $(S)$, one TPL, and two retailers ( $R 1$ and $R 2$ ). Suppliers give the rights of inventory operation and decision to TPL through a contract. TPL is responsible for replenishment and delivery in the total supply chain which means that TPL stores finished products in the warehouse near suppliers and, meanwhile, builds a district distribution center in order to meet retailers' requirements in time. Besides, considering scale effect of transportation, TPL takes a certain delivery strategy in the district distribution center.

Figure 8 mainly describes VMI\&TPL integrated operation mode. Similar to VMI operation mode, the information in the supply chain is shared fully. Retailers share real-time 


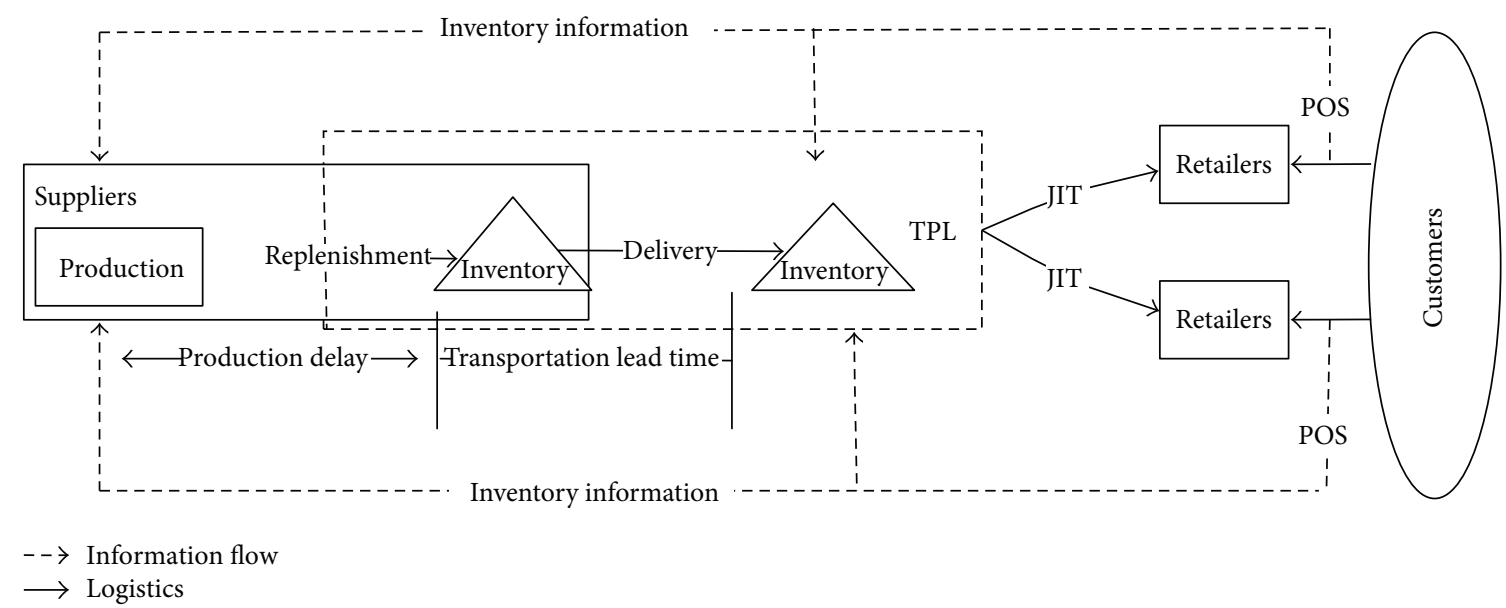

FIGURE 8: VMI\&TPL-APIOBPCS integrated operating model.

sales information with suppliers and TPL. Meanwhile, TPL shares inventory information with suppliers and suppliers provide TPL with production information. It is different from VMI operation mode that TPL is in charge of inventory management in the total supply chain, oversees the inventory level in the whole supply chain, and sends requests for replenishment to suppliers in time so that suppliers can organize capacities to produce according to orders. Besides, TPL organizes transit power and sends products to the district distribution center close to suppliers and to retailers and distributes products to retailers according to sales information and contracts in VMI\&TPL integrated operation mode.

4.1.2. VMIßTPL Operational Process. After carrying out TPL and VMI integrated operation, suppliers are not responsible for concrete logistics activities but give rights of inventory operation and decision to TPL through a contract. Therefore, TPL does not only undertake physical distribution business but is also responsible for orders generated in integrated logistics operation. The operational process of the whole system is illustrated in Figure 9.

(1) TPL updates retailers' inventory information everyday according to inventory information provided by retailers.

(2) TPL makes recommended orders according to retailers' inventory level and service level and replenishment point confirmed in advance.

(3) TPL sends orders to retailers and chooses the proper distribution route according to self-inventory level and retailers' demand after retailers confirm their orders. It is necessary to send requests for replenishment to suppliers and ask them to replenish inventory in time if self-inventory reaches replenishment level.

(4) Suppliers know well about the logistics operational situation by information sharing, then replenish inventory according to TPL's demand, and settle accounts in time according to the orders confirmed by retailers.
TABLE 3: Definitions of parameters and variables.

\begin{tabular}{ll}
\hline ORT: productivity & CRT: production fulfillment rate \\
RPT: replenishment rate & SRT: delivery rate \\
W-ROP: TPL replenishment & D-ROP: TPL redelivery point \\
point & $\begin{array}{l}\text { RINV: retailers' temporary } \\
\text { GIT: TPL transportation } \\
\text { inventory }\end{array}$ \\
\hline
\end{tabular}

4.2. VMIঊTPL-APIOBPCS Model. The definitions of parameters and variables in VMI\&TPL-APIOBPCS model are given in Table 3.

According to the operational structure in Figure 8 and operational process in Figure 9, three subsystems of VMI\&TPL-APIOBPCS models, including suppliers' production subsystem, TPL replenishment and delivery subsystem, and retailers' sales subsystem, are analyzed as follows.

4.2.1. Suppliers' Production Subsystem. As shown in Figure 10, suppliers' production decisions are influenced by three aspects, which are demand information (terminal customer requirements), system inventory level, and work-in-process inventory level.

Difference equations of suppliers' production operational process can be obtained according to the causality in Figure 10 as shown in the following formulas.

Work-in-process:

$$
\mathrm{WIP}_{t}=\mathrm{WIP}_{t-1}+\mathrm{ORT}_{t}-\mathrm{CRT}_{t} .
$$

Work-in-process deviation:

$$
\mathrm{EWIP}_{t}=\mathrm{DWIP}_{t}-\mathrm{WIP}_{t}
$$

Productivity:

$\mathrm{ORT}_{t}=\mathrm{AVCON}_{t-1}+\frac{\mathrm{EINV}_{t-1}}{T_{i}}+\frac{\mathrm{EWIP}_{t-1}}{T_{w}}$. 


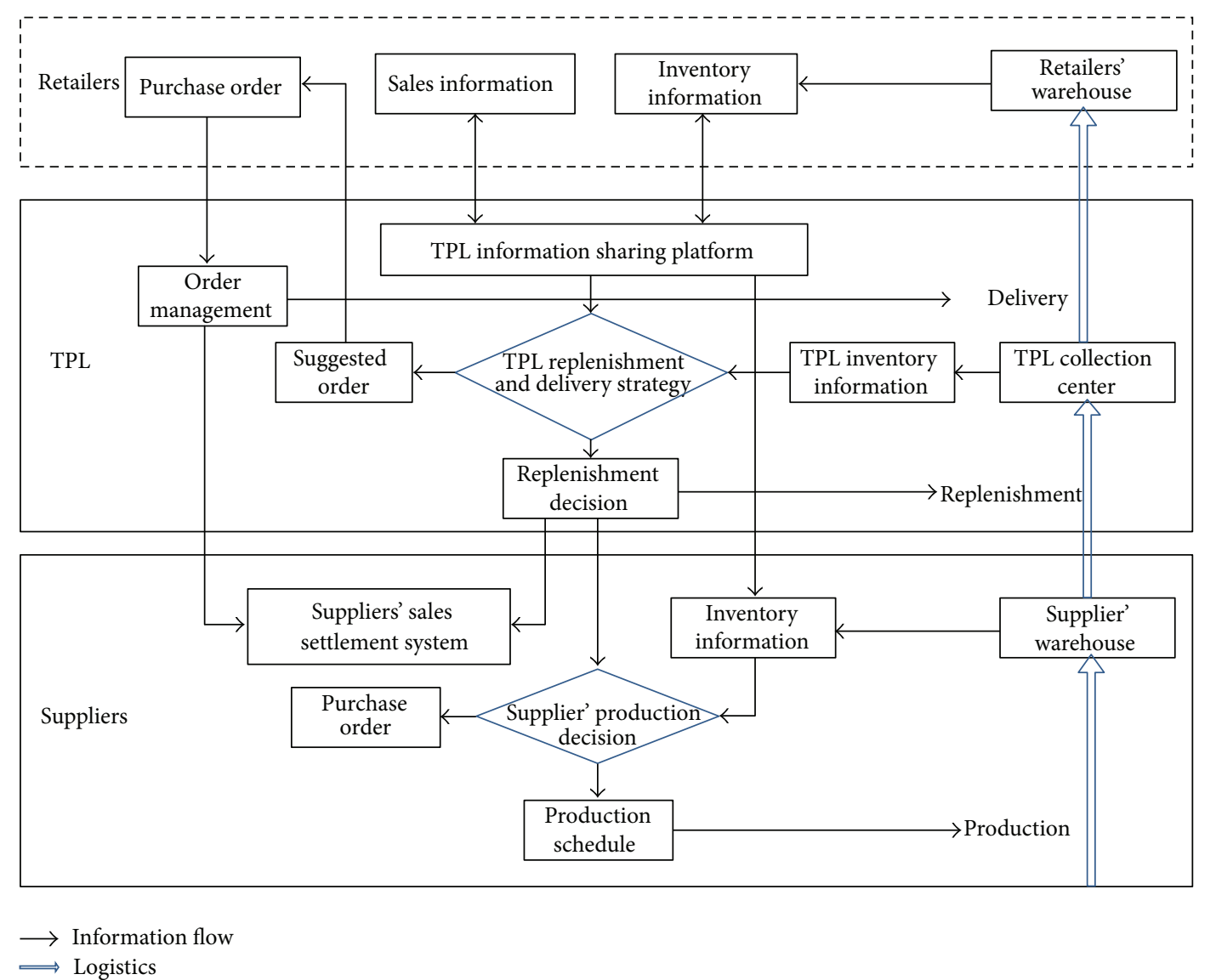

FIGURE 9: VMI\&TPL integrated operation process.

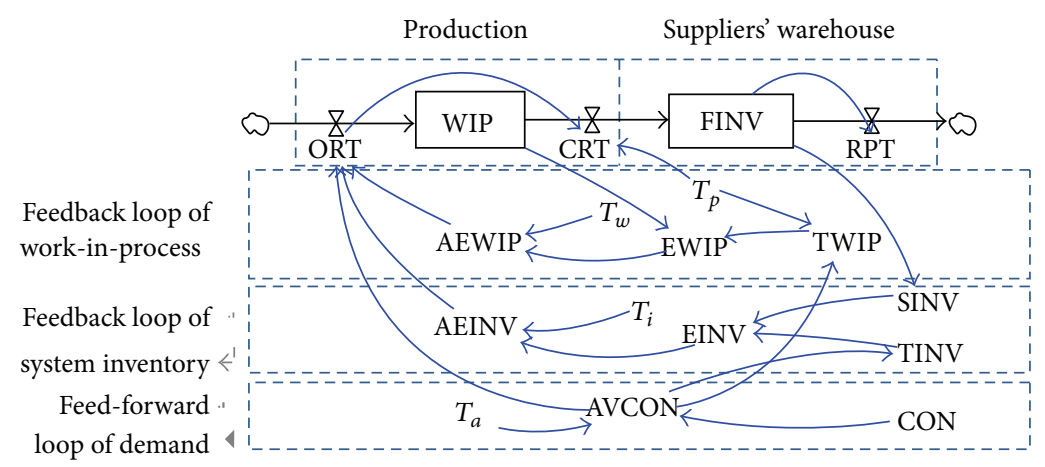

FIGURE 10: Causality diagram of suppliers' production subsystem.

Productivity fulfillment rate:

$$
\mathrm{CRT}_{t}=\mathrm{ORT}_{t-T p}
$$

System inventory deviation:

$$
\mathrm{EINV}_{t}=\mathrm{TINV}-\mathrm{SINV}_{t}
$$

Target system inventory:

$$
\operatorname{TINV}=\operatorname{AVCON} *\left(T_{p}+T_{q}\right) .
$$

4.2.2. TPL Replenishment and Delivery Subsystem. TPL is responsible for replenishment and delivery decisions between suppliers and retailers. On the one hand, TPL sends requests for replenishment to suppliers in order to ensure proper inventory of the TPL warehouse (TPL-W). On the other 


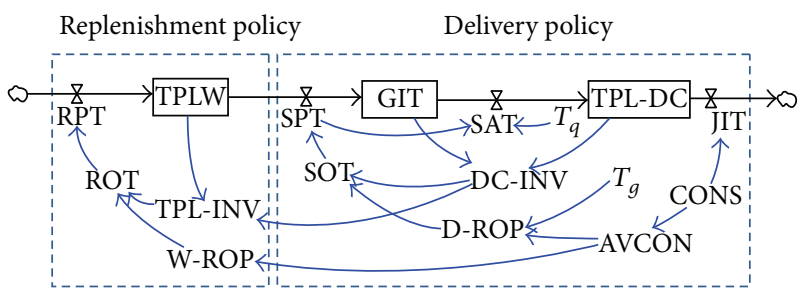

FIGURE 11: TPL replenishment and delivery subsystem causality diagram.

hand, TPL needs to deliver products to the TPL distribution center (TPL-DC) near retailers in order to meet retailers' demand. Figure 11 is TPL replenishment and delivery subsystem causality diagram.

Formulas (30)-(32) are difference equations of TPL replenishment strategy and formulas (33)-(37) are difference equations of TPL delivery strategy.

TPL total inventory level:

$$
\mathrm{TPL}^{-\mathrm{INV}_{t}}=\mathrm{DC}-\mathrm{INV}_{t}+\mathrm{TPLW}_{t} .
$$

TPL-W replenishment point:

$$
\mathrm{W}-\mathrm{ROP}_{t}=\mathrm{AVCON}_{t} \times G_{w} .
$$

TPL replenishment capacity:

$\mathrm{ROT}_{t}$

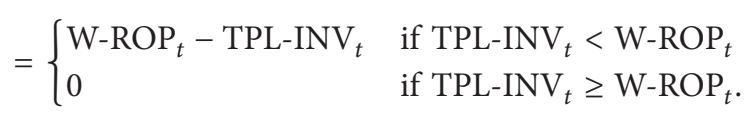

TPL-DC redelivery point:

$$
\mathrm{D}-\mathrm{ROP}_{t}=\mathrm{AVCON}_{t} \times G_{d} .
$$

TPL-DC inventory level:

$$
\mathrm{DC}-\mathrm{INV}_{t}=\mathrm{GIT}_{t}+\mathrm{TPL}-\mathrm{DC}_{t} .
$$

TPL transportation inventory level:

$$
\mathrm{GIT}_{t}=\mathrm{GIT}_{t-1}+\mathrm{SPT}_{t}-\mathrm{SAT}_{t}
$$

$(T, S)$ delivery strategy:

$\mathrm{SOT}_{t}$

$$
= \begin{cases}\mathrm{D}-\mathrm{ROP}_{t}-\mathrm{DC}-\mathrm{INV}_{t} & \text { if DC- } \mathrm{INV}_{t}<\mathrm{D}-\mathrm{ROP}_{t} \\ 0 & \text { if DC- }-\mathrm{INV}_{t} \geq \mathrm{D}-\mathrm{ROP}_{t}\end{cases}
$$

$(R, Q)$ delivery strategy:

$$
\mathrm{SOT}_{t}= \begin{cases}n * \mathrm{ETQ} & \text { if } \mathrm{DC}-\mathrm{INV}_{t}<\mathrm{D}-\mathrm{ROP}_{t} \\ 0 & \text { if } \mathrm{DC}-\mathrm{INV}_{t} \geq \mathrm{D}-\mathrm{ROP}_{t} .\end{cases}
$$

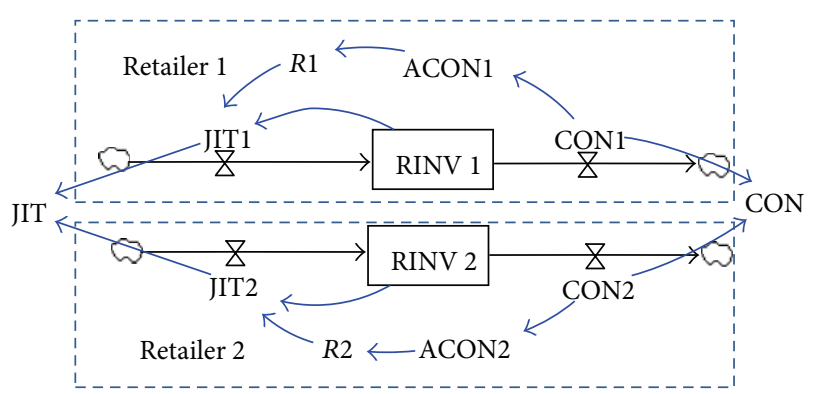

FIGURE 12: Retailers' sales subsystem causality diagram.

4.2.3. Retailers' Sales Subsystem. Retailers' sales subsystem is relatively simple. Though TPL can adopt JIT delivery to retailers, as service level should be improved, retailers still need to keep a small quantity of safety inventory and this inventory level is related to the demand fluctuation level. Figure 12 is retailers' sales subsystem causality diagram.

According to the retailer's sales system causal diagram, the difference equations for retailers can be obtained as follows:

$$
\begin{gathered}
R 1=\mathrm{AVCON}_{t} \times G_{1}, \quad R 2=\mathrm{AVCON} 2_{t} \times G_{2}, \\
\mathrm{JIT} 1_{t}=R 1_{t}-\mathrm{RINV}_{t}, \quad \mathrm{JIT} 2_{t}=R 2_{t}-\mathrm{RINV}_{t}, \\
\mathrm{CONS}_{t}=\mathrm{CON}_{t}+\mathrm{CON} 2_{t}, \\
\mathrm{JIT}_{t}=\mathrm{JIT}_{t}+\mathrm{JIT}_{t} .
\end{gathered}
$$

4.2.4. VMIঊTPL-APIOBPCS System Dynamics Model. According to the aforementioned analysis, VMI\&TPLAPIOBPCS system dynamics model is constructed as shown in Figure 13.

\section{Simulation Analysis}

According to the aforementioned VMI\&TPL-APIOBPC system dynamics model, the two different conditions with phase-step and random demands are investigated, respectively, and parameter settings are as follows.

(1) Production subsystem parameters settings. Referring to that of Disney and Towill $[24,25], T_{a}=4, T_{i}=14$, $T_{w}=8$, and $T_{p}=5$.

(2) Parameters settings of replenishment and delivery subsystem, $G_{w}=8, G_{d}=5, \mathrm{ETQ}=10$, and $T_{q}=5$.

(3) Parameters settings of sales subsystem, $G_{1}=3, G_{2}=$ 3.

Then simulate the two models, VMI-APIOBPCS II and VMI\&TPL-APIOBPCS, using Vensim, and run the test for 100 units of time (month).

5.1. Phase-Step Demand Test. The demand test functions CONS1 and CONS2 are both phase-step functions, CONS1 = STEP $(5,0)(\operatorname{STEP}(\{$ height $\},\{$ stime $\}))$, CONS2 $=$ STEP $(10,10)$. 


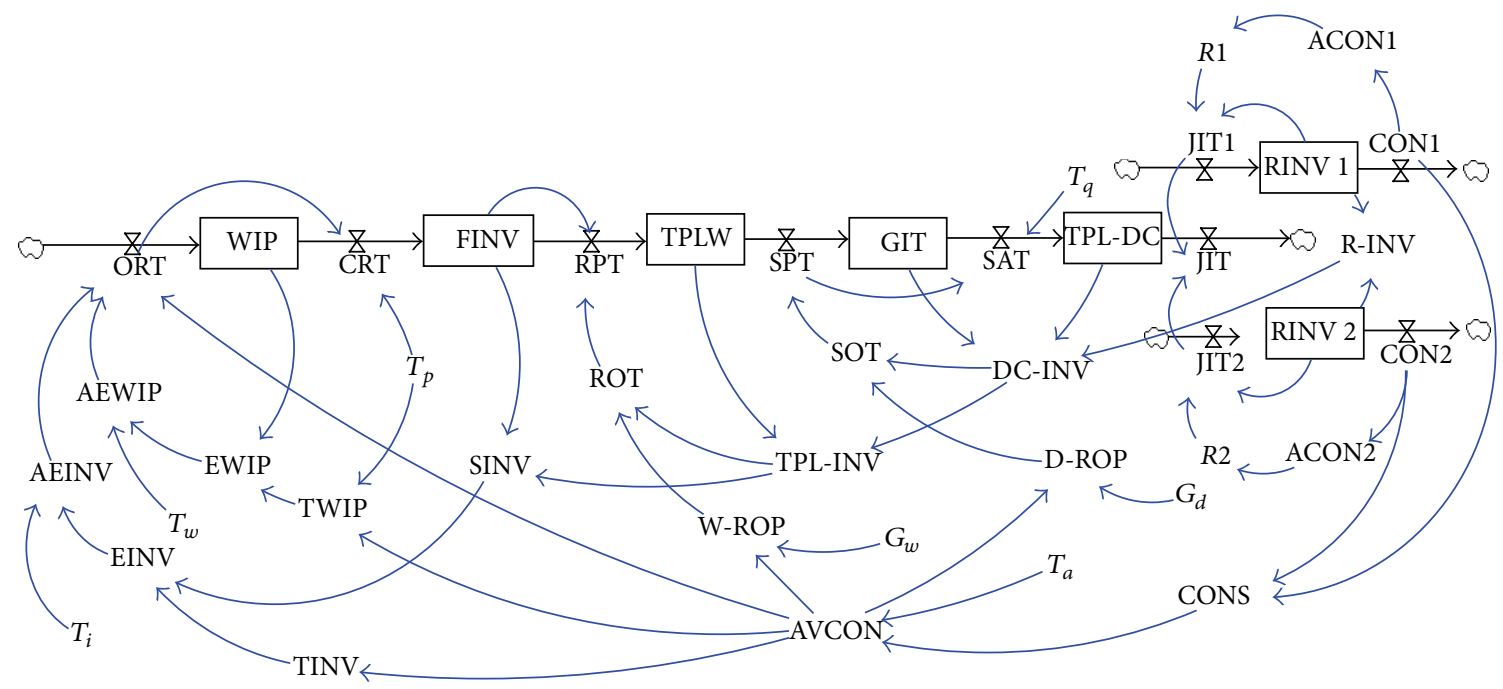

FIGURE 13: VMI\&TPL-APIOBPCS model causality diagram.

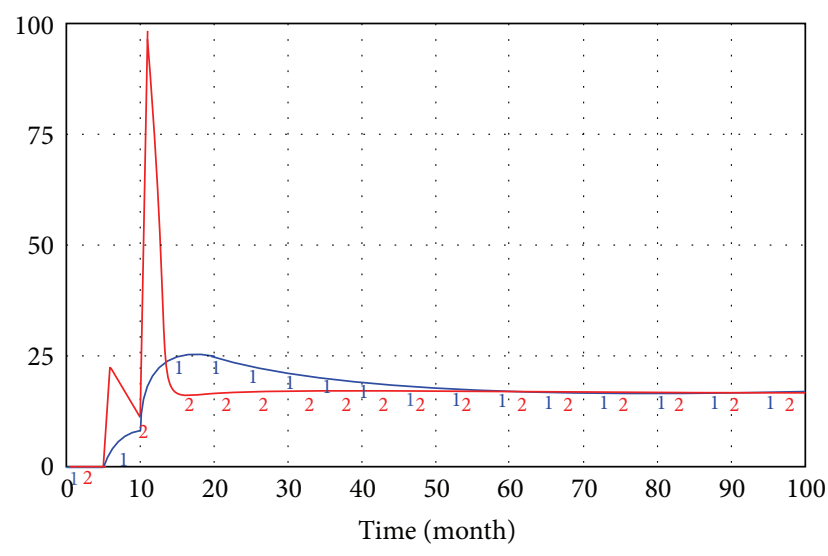

ORT: VMI and TPL-APIOBPCS

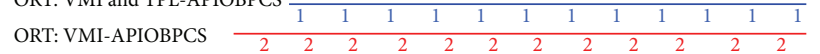

FIGURE 14: Comparison of production fluctuations in suppliers' production orders.

5.1.1. Fluctuations of Production Order. As shown in Figure 14, when TPL is introduced into VMI, suppliers' productivity becomes smoother, which is mostly due to the smoother system inventory levels. In the meanwhile, the response time of productivity reaching the steady-state in the VMI\&TPL-APIOBPCS model is relatively longer.

\subsubsection{Fluctuations of Inventory Level}

(1) System inventory levels. As shown in Figure 15, in VMI\&TPL-APIOBPCS model, the system inventory level significantly decreases and becomes smoother. Under phase-step demand, the two model system inventories in models gradually return to a steady-state value $(\mathrm{TINV}=150)$ and are similar to the suppliers' productivity. The response time of system inventory level reaching the steady-state in VMI\&TPL-APIOBPCS model is relatively longer.

(2) Suppliers' inventory level. Figure 16 is the suppliers' inventory level. After introducing TPL, suppliers' inventory level is effectively smoothed and reduced, which is because that the fluctuation of downstream replenishment batch is more consistent compared to that in VMI model; see Figure 17.

(3) Comparison of downstream overall inventory level. In VMI-APIOBPCS model, the downstream inventory mainly includes retailers' inventories. However, in the VMI\&TPL-APIOBPCS model, the downstream inventory includes not only the retailers' safety stock but also the inventory in TPL warehouse and distribution center. Figure 18 is the downstream inventory level. After introducing TPL, the downstream inventory level (including the TPL) increases slightly, largely because the downstream structure is added with a new subject (TPL).

From the aforementioned inventory analysis, we can know that after introducing TPL into VMI supply chain, although supply chains add an echelon, the downstream inventory level increases slightly, but the replenishment batch becomes smoother after TPL's participation, thus effectively smoothing suppliers' productivity and reducing supplier inventory levels.

5.1.3. Comparison of Service Level. What defines service level of retailers is the ratio between the retailers' inventory level and customers' demand. Figures 19 and 20 are the service level of the two operation modes, respectively. Since the initial state of the system is zero, the initial service level of the retailers is zero, and the service level gradually improves after a period of time. In VMI operation mode, the average service levels of two retailers are $61.5 \%$ and $46.2 \%$, respectively. In VMI\&TPL 


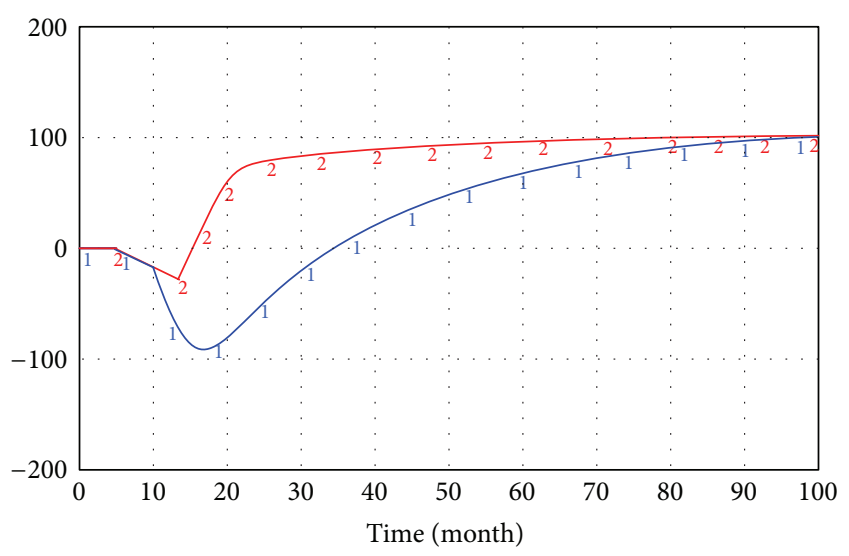

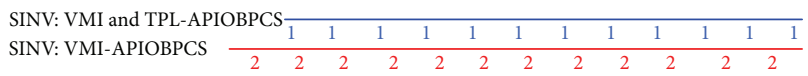

FIGURE 15: The comparison of system inventory level fluctuation.

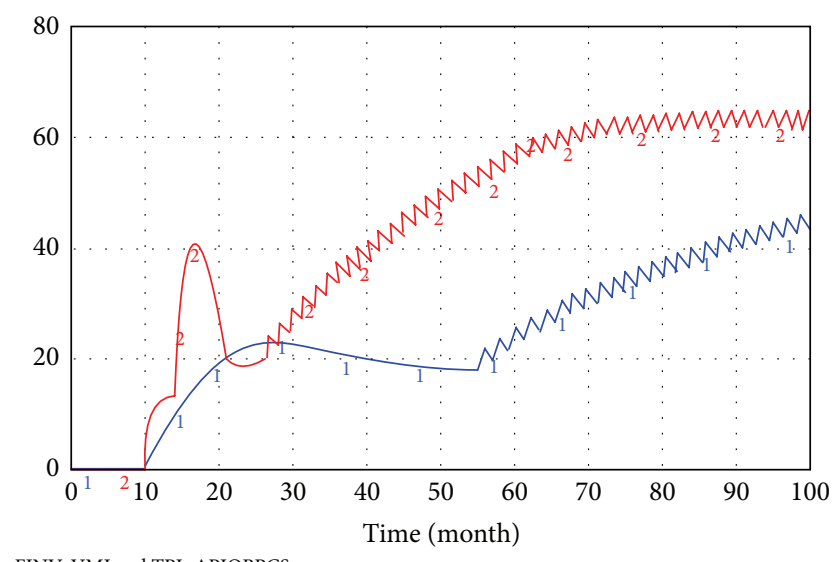

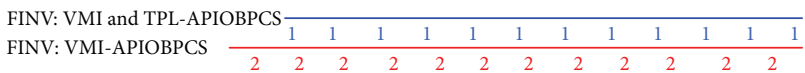

FIGURE 16: The comparison of supplier inventory level fluctuation.

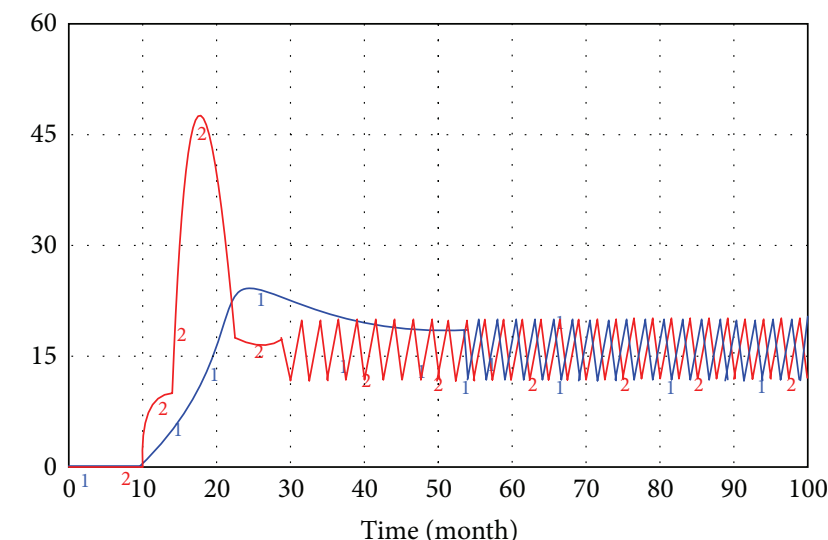

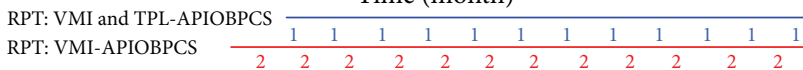

FIGURE 17: The comparison of replenishment batch fluctuation.

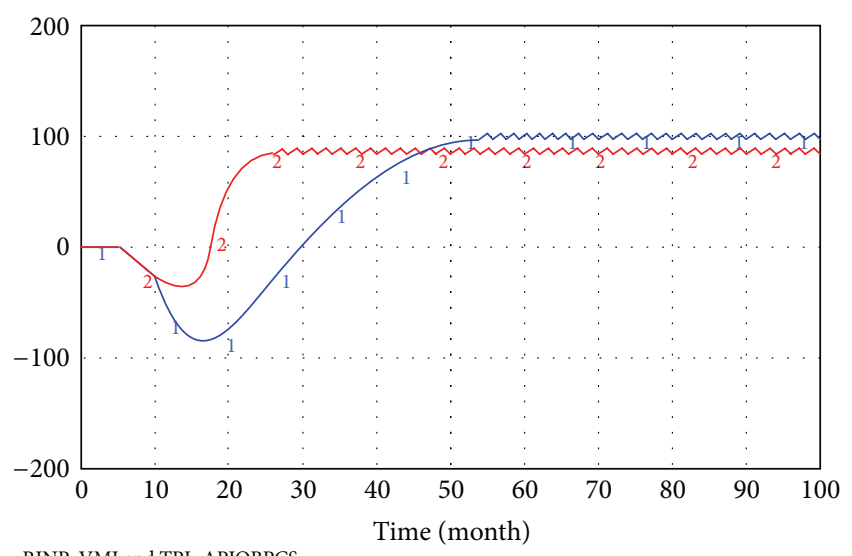

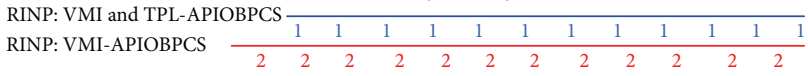

FIgURE 18: The comparison of downstream inventory level fluctuation.

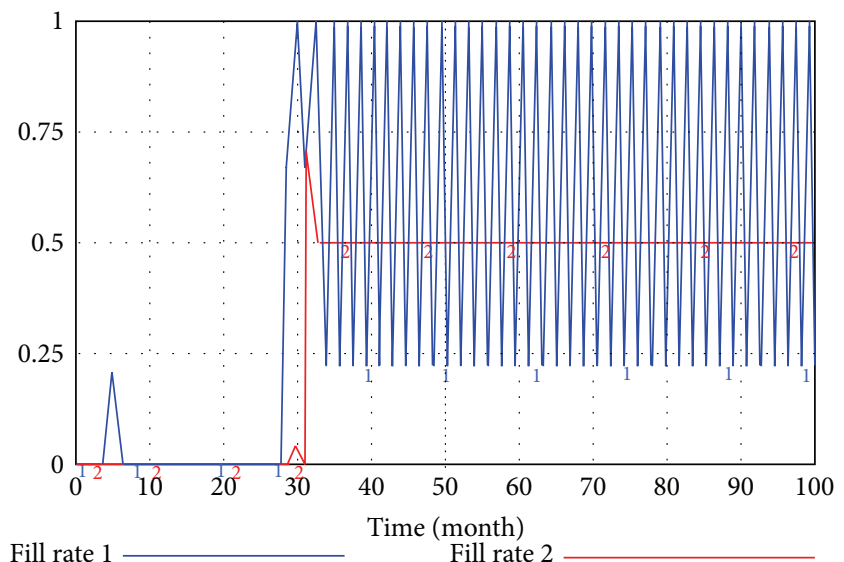

FIGURE 19: Service levels in the VMI operation mode.

integrated operation mode, the average service level of two retailers is $58.5 \%$.

With the deterministic demand, service level of the first retailer falls slightly, but the second retailer's service level increases substantially, and the overall average service level of retailers improves after introducing TPL. However, the response time of the system increases, because the system service level will not be enhanced till a long period of shortage.

5.2. Random Demand Test. The demand test functions, such as CONS1 and CONS2, are both phase-step functions. CONS1 $=$ RANDOM NORMAL $(0,10,5,20,1)($ RANDOM NORMAL $(\{\min \},\{\max \},\{$ mean $\},\{$ stdev $\},\{$ seed $\}))$, CONS2 $=$ RANDOM NORMAL $(0,5,3,10,1)$.

5.2.1. Suppliers' Productivity. Similar to the phase-step demand situation, supplier's productivity is steadier apparently in VMI\&TPL-APIOBPCS mode. 


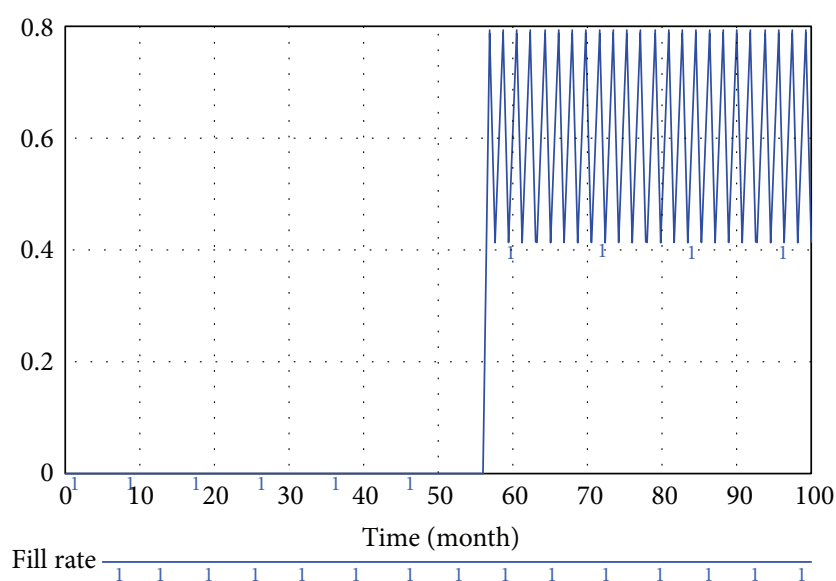

FIgURE 20: Service levels in the VMI\&TPL integrated operation mode.

\subsubsection{Comparison of Inventory Levels}

(1) System inventory level. As Figure 22 shows, compared with the VMI model, the system inventory level in VMI\&TPL-APIOBPCS model is lower and largely benefits from the dramatical decrease of suppliers' inventory level, as shown in Figure 23.

(2) Suppliers' inventory levels. As Figure 23 shows, in VMI\&TPL-APIOBPCS model, suppliers' inventory levels are significantly reduced as suppliers' productivity becomes smoother, and TPL replenishment batch is steadier compared to VMI model.

(3) Downstream inventory level: As Figure 24 shows, in VMI\&TPL-APIOBPCS model, the downstream inventory level increases slightly due to an additional echelon of TPL with concentrated restocking and delivery in supply chain.

5.2.3. Comparison of Service Level. Under the random demand and in the operation mode of VMI the first retailer's average service level is $78.6 \%$ and the second retailer's average service level is $40.4 \%$.

In the VMI\&TPL integrated operation mode, the overall service levels of the two retailers are $94.8 \%$. It is clear that after introducing TPL the two service levels of retailers are improved under random demand; this benefits from the risksharing effect in centralized inventory after the introduction of TPL.

5.3. Simulation Discussion. The complex simulations under phase-step demand and random demand show the following results as this study summarized from the follow-up interviews in practice.

First, VMI\&TPL integrated operation mode can smoothen suppliers' productivity under both phase-step demand and random demand as TPL introduced into VMI makes the whole system inventory levels smoother (see Figure 21). However, the response time of reaching the steady-state in the VMI\&TPL-APIOBPCS model is relatively

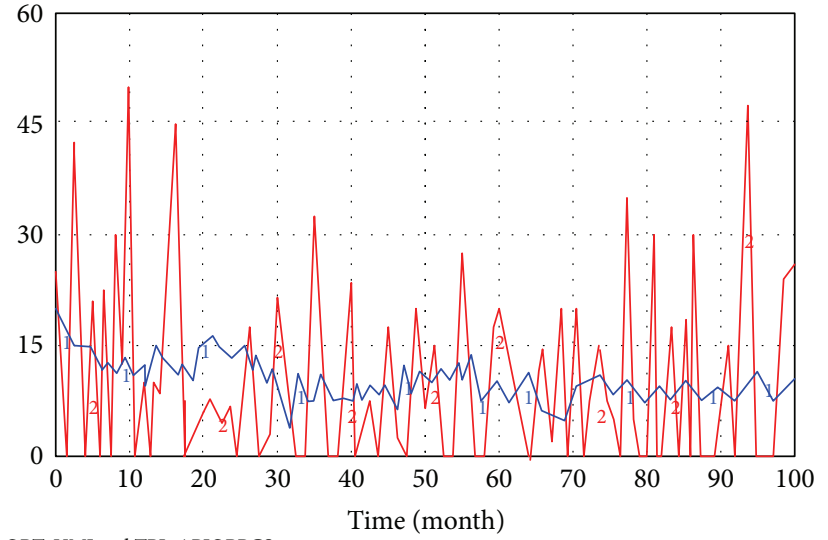

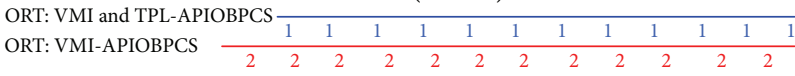

FIGURE 21: Fluctuation diagram of suppliers' productivity.

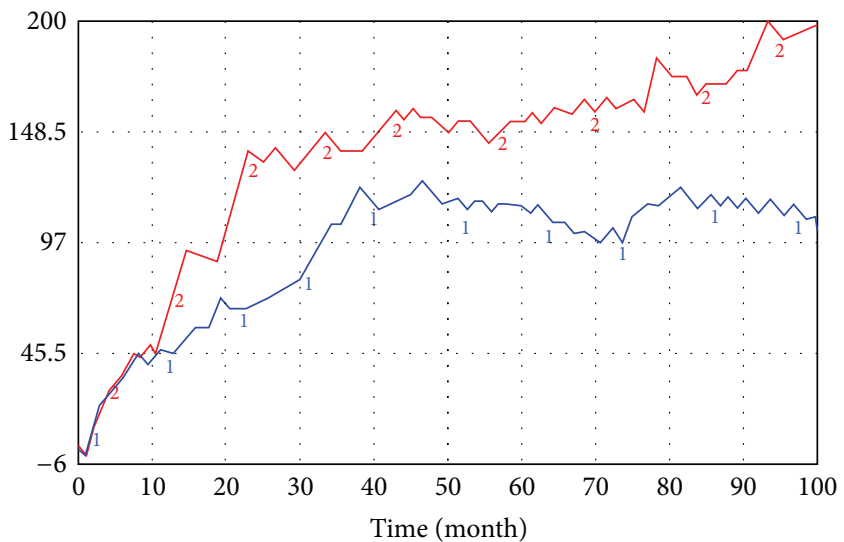

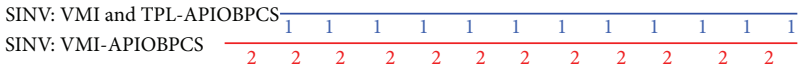

FIGURE 22: Fluctuation diagram of system inventory level.

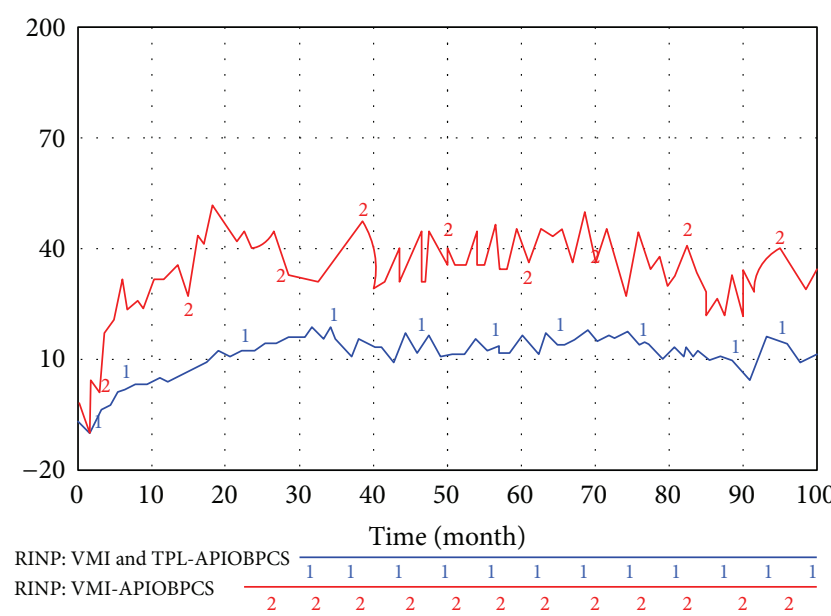

Figure 23: Fluctuation diagram of suppliers' inventory level. 


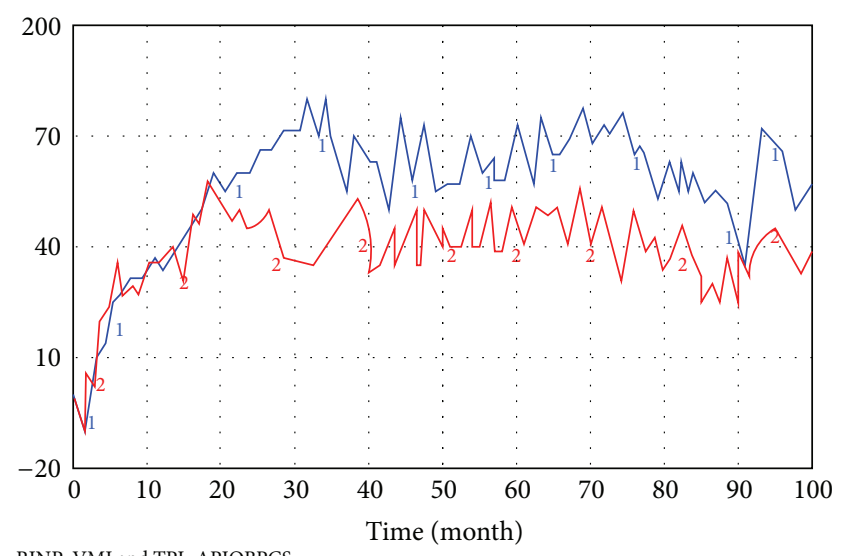

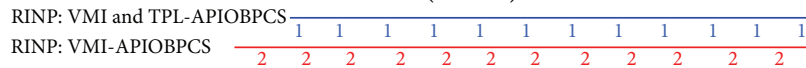

FIGURE 24: Fluctuation diagram of lower inventory level.

longer, which may be caused by TPL centralized operation. Particularly, the fluctuation of suppliers' productivity under random demand is more stable than under phase-step demand, as in practice TPL places orders from suppliers periodically, and its response to fluctuation is slow.

Second, VMI\&TPL integrated operation mode can reduce the system inventory level significantly. Similarly, the response time of system inventory level reaching the steadystate in VMI\&TPL-APIOBPCS model is relatively longer. Compared with under phase-step demand, system inventory level can be lower under random demand. This illustrates that the TPL centralized replenishment has a scale of economics and much risk pooling effects which can decrease the whole system inventory level [37]. Besides, suppliers' inventory level is effectively smoothed and reduced since downstream replenishment batch is more consistent and scale of economics compared to those in VMI model. However, in the VMI\&TPL-APIOBPCS model, the downstream inventory includes not only the retailers' safety stock but also the inventory in TPL warehouse and distribution center. As a result, the downstream inventory level rises slightly after introducing TPL.

Third, VMI\&TPL integrated operation mode can improve average service level. Under phase-step demand, service level of the first retailer falls slightly, but the second retailer's service level increases substantially. As a contrast, service level of two retailers increases under random demand. On the whole, the service level under random demand is improved significantly than under phase-step demand (see Figures 25 and 26). These may be caused by risk pooling effect, especially under random demand.

\section{Conclusion}

This paper constructs the VMI\&TPL-APIOBPCS model after introducing TPL into VMI distribution based on VMIAPIOBPCS system dynamics model. The system performance of VMI\&TPL integrated supply chain under phasestep and random demand is considered. The simulation

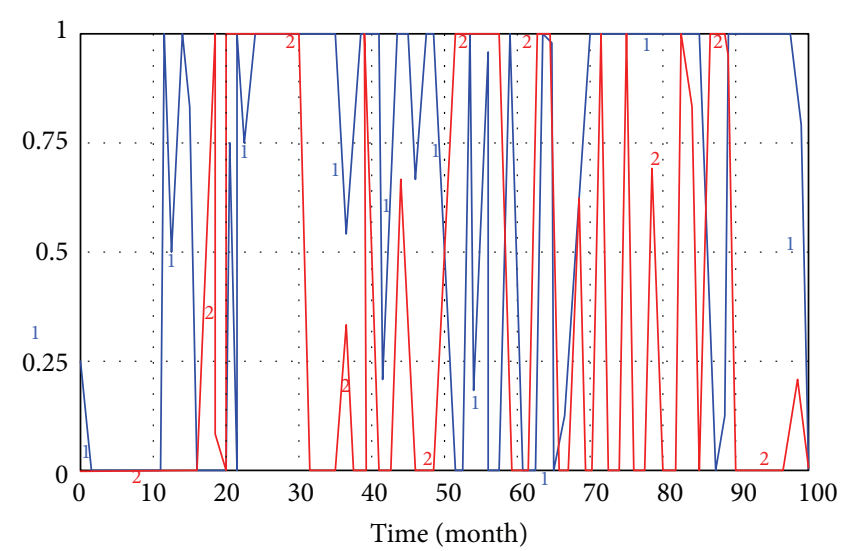

\begin{tabular}{lcccccccccccccr} 
& \multicolumn{10}{c}{ Time (month) } \\
\cline { 2 - 11 } & & 1 & 1 & 1 & 1 & 1 & 1 & 1 & 1 & 1 & 1 & 1 & 1 \\
\hline Fr2: VMI-APIOBPCS & 2 & 2 & 2 & 2 & 2 & 2 & 2 & 2 & 2 & 2 & 2 & 2
\end{tabular}

FIGURE 25: The service level of VMI operational model under random demand.

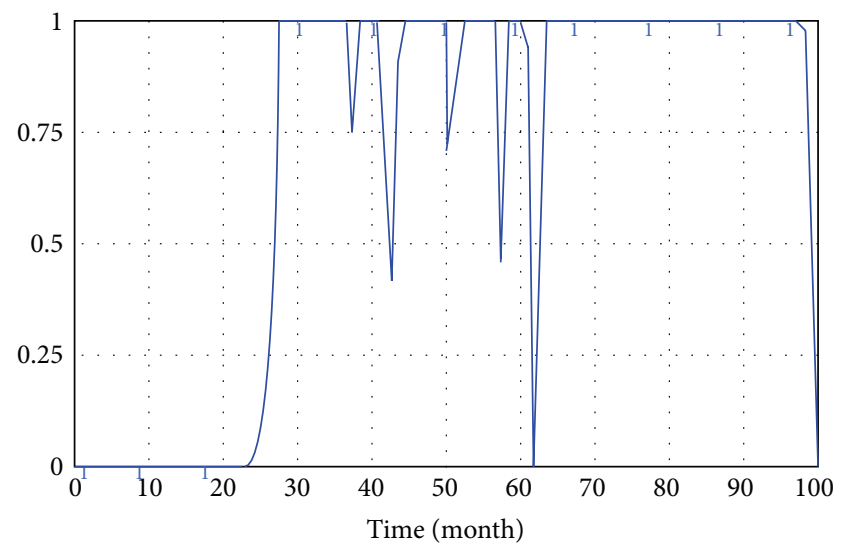

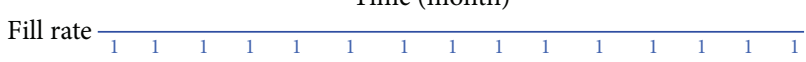

FIGURE 26: The service level of VMI\&TPL integrated operational model under random demand.

analysis shows that though the supply chain is turned into a three-echelon structure from a two-echelon one TPL can effectively smooth the replenishment and delivery quantity between suppliers and retailers by goods collection, thus dramatically reducing the inventory level of the suppliers and the whole system, effectively smoothing the production rhythm of suppliers and improving the service level of customers.

Although system dynamics method can describe and simulate VMI\&TPL integrated operational model, it lacks the optimization of TPL replenishment and delivery policy in this operation mode. As a result, it is necessary to optimize the TPL replenishment and delivery policy under various demands using mathematical programming and optimization theories, so as to enhance the study of VMI\&TPL integrated operational model further. 


\section{Acknowledgments}

This work was supported by the National Natural Science Foundation of China (no. 71102174, 71372019), Beijing Natural Science Foundation of China (no. 9123028, 9102016), Specialized Research Fund for Doctoral Program of Higher Education of China (no. 20111101120019), Beijing Philosophy \& Social Science Foundation of China (no. 11JGC106), Program for New Century Excellent Talents in University of China (no. NCET-10-0048, NCET-10-0043), and Excellent Young Teacher in Beijing Institute of Technology of China (no. 2010YC1307).

\section{References}

[1] S. Çetinkaya and C.-Y. Lee, "Stock replenishment and shipment scheduling for vendor-managed inventory systems," Management Science, vol. 46, no. 2, pp. 217-232, 2000.

[2] S. Çetinkaya and C.-Y. Lee, "Optimal outbound dispatch policies: modeling inventory and cargo capacity," Naval Research Logistics, vol. 49, no. 6, pp. 531-556, 2002.

[3] C.-Y. Lee, S. Çetinkaya, and W. Jaruphongsa, "A dynamic model for inventory lot sizing and outbound shipment scheduling at a third-party warehouse," Operations Research, vol. 51, no. 5, pp. 735-837, 2003.

[4] S. Çetinkaya, F. Mutlu, and C.-Y. Lee, "A comparison of outbound dispatch policies for integrated inventory and transportation decisions," European Journal of Operational Research, vol. 171, no. 3, pp. 1094-1112, 2006.

[5] F. Mutlu, S. Çetinkaya, and J. H. Bookbinder, "An analytical model for computing the optimal time-and-quantity-based policy for consolidated shipments," IIE Transactions, vol. 42, no. 5, pp. 367-377, 2010.

[6] S. Çetinkaya and J. H. Bookbinder, "Stochastic models for the dispatch of consolidated shipments," Transportation Research B, vol. 37, no. 8, pp. 747-768, 2003.

[7] J. Dejonckheere, S. M. Disney, M. R. Lambrecht, and D. R. Towill, "Transfer function analysis of forecasting induced bullwhip in supply chains," International Journal of Production Economics, vol. 78, no. 2, pp. 133-144, 2002.

[8] W. Jaruphongsa, S. Çetinkaya, and C.-Y. Lee, "A two-echelon inventory optimization model with demand time window considerations," Journal of Global Optimization, vol. 30, no. 4, pp. 347-366, 2004.

[9] W. Jaruphongsa, S. Çetinkaya, and C.-Y. Lee, "A dynamic lotsizing model with multi-mode replenishments: polynomial algorithms for special cases with dual and multiple modes," IIE Transactions, vol. 37, no. 5, pp. 453-467, 2005.

[10] W. Jaruphongsa, S. Çetinkaya, and C.-Y. Lee, "Outbound shipment mode considerations for integrated inventory and delivery lot-sizing decisions," Operations Research Letters, vol. 35, no. 6, pp. 813-822, 2007.

[11] W. Jaruphongsa and C.-Y. Lee, "Dynamic lot-sizing problem with demand time windows and container-based transportation cost," Optimization Letters, vol. 2, no. 1, pp. 39-51, 2008.

[12] C.-Y. Lee, "Inventory replenishment model: lot sizing versus just-in-time delivery," Operations Research Letters, vol. 32, no. 6, pp. 581-590, 2004.

[13] H.-C. Hwang, "Economic lot-sizing for integrated production and transportation," Operations Research, vol. 58, no. 2, pp. 428$444,2010$.
[14] C. Howard and J. Marklund, "Evaluation of stock allocation policies in a divergent inventory system with shipment consolidation," European Journal of Operational Research, vol. 211, no. 2, pp. 298-309, 2011.

[15] M. Ç. Gürbüz, K. Moinzadeh, and Y.-P. Zhou, "Coordinated replenishment strategies in inventory/distribution systems," Management Science, vol. 53, no. 2, pp. 293-307, 2007.

[16] L. E. Cárdenas-Barrón, G. Treviño-Garza, and H. M. Wee, "A simple and better algorithm to solve the vendor managed inventory control system of multi-product multi-constraint economic order quantity model," Expert Systems with Applications, vol. 39, no. 3, pp. 3888-3895, 2012.

[17] J. Sadeghia, S. M. Mousavib, S. T. A. Niakic, and S. Sadeghid, "Optimizing a multi-vendor multi-retailer vendor managed inventory problem: two tuned meta-heuristic algorithms," Knowledge-Based Systems, vol. 50, no. 9, pp. 159-170, 2013.

[18] M. Hariga, M. Gumus, A. Daghfous, and S. K. Goyal, "A vendor managed inventory model under contractual storage agreement," Computers \& Operations Research, vol. 40, no. 8, pp. 2138-2144, 2013.

[19] D. R. Towill, "Dynamic analysis of an inventory and order based production control system," International Journal of Production Research, vol. 20, pp. 369-383, 1982.

[20] J. W. Forrester, "Industrial dynamics: a major breakthrough for decision makers," Harvard Business Review, vol. 36, no. 1, pp. 37-66, 1958.

[21] J. D. Sterman, "Modeling managerial behavior: misperceptions of feedback in a dynamic decision making experiment," Management Science, vol. 35, no. 3, pp. 321-339, 1989.

[22] S. John, M. M. Naim, and D. R. Towill, "Dynamic analysis of a WIP compensated decision support system," International Journal of Manufacturing System Design, vol. 1, no. 4, pp. 283297, 1994.

[23] R. Mason-Jones, M. M. Naim, and D. R. Towill, "The impact of pipeline control on supply chain dynamics," The International Journal of Logistics Management, vol. 8, no. 2, pp. 47-61, 1997.

[24] S. M. Disney and D. R. Towill, "A procedure for the optimization of the dynamic response of a Vendor Managed Inventory system," Computers and Industrial Engineering, vol. 43, no. 1-2, pp. 27-58, 2002.

[25] S. M. Disney and D. R. Towill, "A discrete transfer function model to determine the dynamic stability of a vendor managed inventory supply chain," International Journal of Production Research, vol. 40, no. 1, pp. 179-204, 2002.

[26] S. M. Disney and D. R. Towill, "On the bullwhip and inventory variance produced by an ordering policy," Omega, vol. 31, no. 3, pp. 157-167, 2003.

[27] S. M. Disney and D. R. Towill, "The effect of vendor managed inventory (VMI) dynamics on the Bullwhip Effect in supply chains," International Journal of Production Economics, vol. 85, no. 2, pp. 199-215, 2003.

[28] S. M. Disney and D. R. Towill, "Vendor-managed inventory and bullwhip reduction in a two-level supply chain," International Journal of Operations and Production Management, vol. 23, no. 5-6, pp. 625-651, 2003.

[29] J. Wikner, "Dynamic analysis of a production-inventory model," Kybernetes, vol. 34, no. 6, pp. 803-823, 2005.

[30] H. Chen, Y. Han, and B. Wang, "The study of inventory management based on system dynamics," Journal of Industrial Engineering and Engineering Management, vol. 19, no. 3, pp. 132140, 2005. 
[31] Y. Yang and Z. Liu, "A system dynamic model of vendor managed inventory and third party logistics," System Engineering, vol. 25, no. 7, pp. 38-44, 2007.

[32] S. Cho and A. Lazaro, "Control theoretic model using PID controller for just-in-time production scheduling," The International Journal of Advanced Manufacturing Technology, vol. 51, no. 5-8, pp. 699-709, 2010.

[33] K.-P. Lin, P.-T. Chang, K.-C. Hung, and P.-F. Pai, "A simulation of vendor managed inventory dynamics using fuzzy arithmetic operations with genetic algorithms," Expert Systems with Applications, vol. 37, no. 3, pp. 2571-2579, 2010.

[34] D. Kastsian and M. Mönnigmann, "Optimization of a vendor managed inventory supply chain with guaranteed stability and robustness," International Journal of Production Economics, vol. 131, no. 2, pp. 727-735, 2011.

[35] Y. Kristianto, P. Helo, J. Jiao, and M. Sandhu, "Adaptive fuzzy vendor managed inventory control for mitigating the Bullwhip effect in supply chains," European Journal of Operational Research, vol. 216, no. 2, pp. 346-355, 2012.

[36] Y. Kristianto, A. Gunasekaran, P. Helo, and M. Sandhu, "A decision support system for integrating manufacturing and product design into the reconfiguration of the supply chain networks," Decision Support Systems, vol. 52, no. 4, pp. 790-801, 2012.

[37] M. Li and J. Zhang, "Does inventory pooling improve customer service levels?" Operations Research Letters, vol. 40, no. 2, pp. 96-98, 2012. 


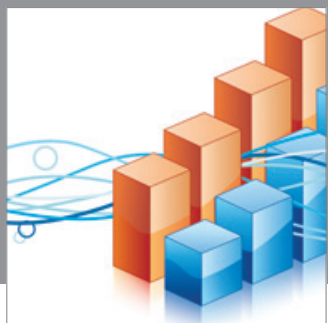

Advances in

Operations Research

mansans

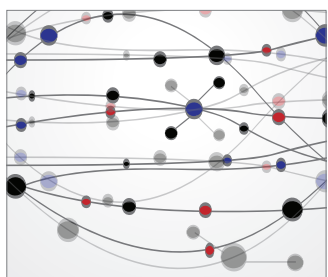

The Scientific World Journal
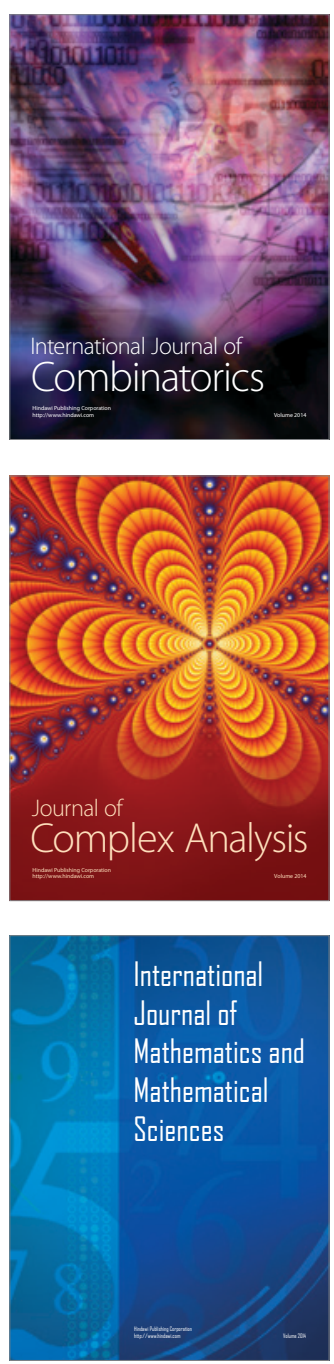
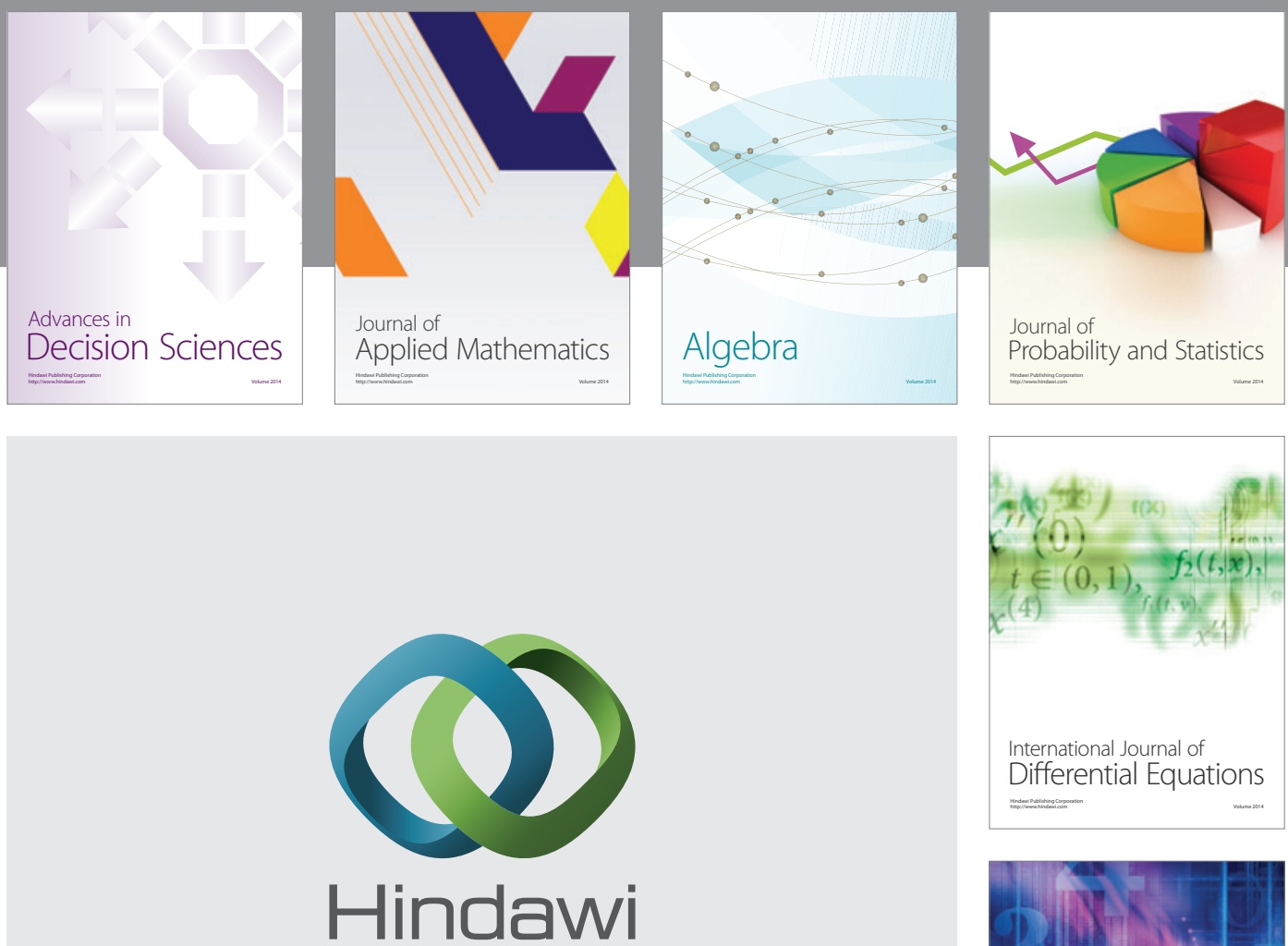

Submit your manuscripts at http://www.hindawi.com
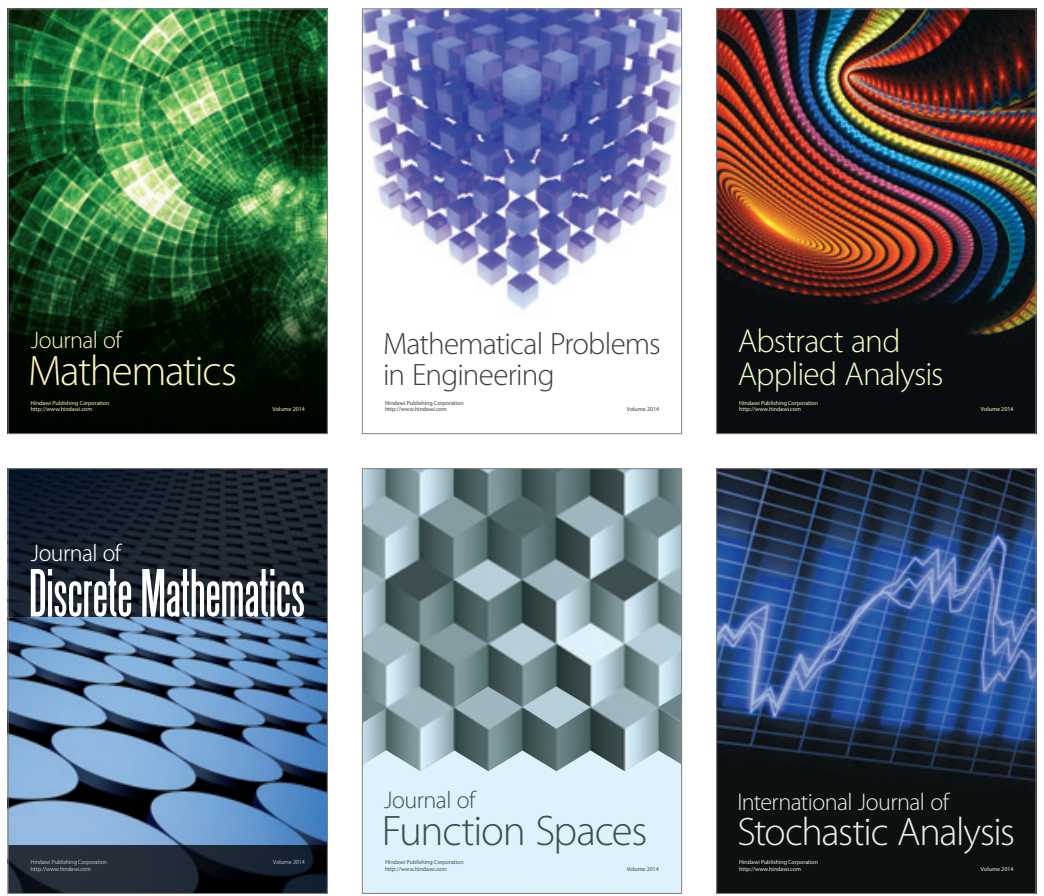

Journal of

Function Spaces

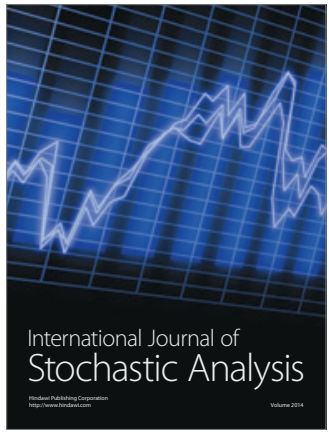

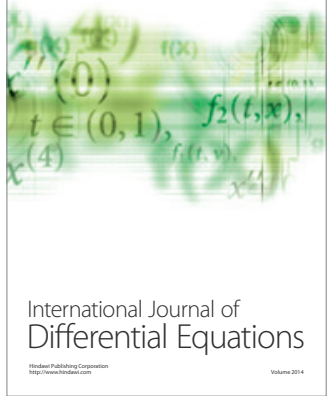
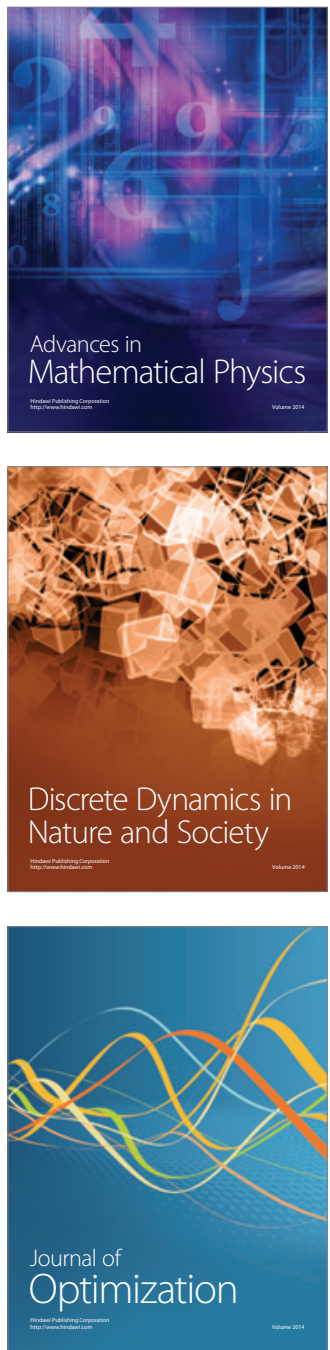